Article

\title{
Emulation Strategies and Economic Dispatch for Inverter-Based Renewable Generation under VSG Control Participating in Multiple Temporal Frequency Control
}

\author{
Weichao Zhang ${ }^{1, *}$, Xiangwu Yan ${ }^{1, *}$ and Hanyan Huang ${ }^{2}$ \\ 1 Key Laboratory of Distributed Energy Storage and Micro-Grid of Hebei Province, North China Electric \\ Power University, Baoding 071000, China \\ 2 State Key Laboratory of Alternate Electrical Power System with Renewable Energy Sources, \\ North China Electric Power University, Beijing 102206, China; huanghanyan@ncepu.edu.cn \\ * Correspondence: huuuy@ncepu.edu.cn (W.Z.); xiangwuy@ncepu.edu.cn (X.Y.)
}

Received: 30 December 2019; Accepted: 11 February 2020; Published: 14 February 2020

\begin{abstract}
As the increasing penetration of inverter-based generation (IBG) and the consequent displacement of traditional synchronous generators (SGs), the system stability and reliability deteriorate for two reasons: first, the overall inertia decreases since the power electronic interfaces (PEIs) are almost inertia-less; second, renewable generation profiles are largely influenced by stochastic meteorological conditions. To strengthen power systems, the concept of the virtual synchronous generator (VSG) has been proposed, which controls the external characteristics of PEIs to emulate those of SGs. Currently, PEIs could perform short-term inertial and primary frequency responses through the VSG algorithm. For renewable energy sources (RES), deloading strategies enable the generation units to possess active power reserves for system frequency responses. Additionally, the deloading strategies could provide the potential for renewable generation to possess long-term frequency regulation abilities. This paper focuses on emulation strategies and economic dispatch for IBG units to perform multiple temporal frequency control. By referring to the well-established knowledge systems of generation and operation in conventional power systems, the current VSG algorithm is extended and complemented by the emulation of secondary and tertiary regulations. The reliability criteria are proposed, considering the loss of load probability (LOLP) and renewable spillage probability (RSP). The reliability criteria are presented in two scenarios, including the renewable units operated in maximum power point tracking (MPPT) and VSG modes. A LOLP-based economic dispatch (ED) approach is solved to acquire the generation and reserve schemes. The emulation strategies and the proposed approach are verified by simulation.
\end{abstract}

Keywords: economic dispatch; inverter-based generation; loss-of-load probability; reserve; virtual synchronous generator

\section{Introduction}

Renewable energy, such as photovoltaics and wind power, has been widely utilized in power systems to tackle environmental crises and to sustain economic development during the past few decades $[1,2]$. Iceland and Norway obtain essentially all of their electricity from renewable sources, and other nations and regions are evolving towards 100\% renewables [3]. According to the 2018 BP energy outlook, sustained support for renewables would lead to strong growth in the share of renewables, reaching $25 \%$ of total energy consumption by 2040 [4]. Therefore, conventional power systems are evolving towards high penetration of renewable generation. However, the characteristics of 
renewable generation $(R G)$ are incompatible with traditional power plants. On the one hand, RG (such as solar photovoltaic and wind power) is commonly integrated through voltage-sourced inverters (VSIs), which are almost inertia-less due to their fast switches. On the other, renewable generation profiles, influenced by meteorological disturbances, are stochastic and fluctuant. Correspondingly, RG integration brings great challenges, including frequency stability and reliability.

The frequency stability of the power system is highly associated with the inertia property, which is a key indicator for evaluating system strength. The inertia property could slow down the rate of change of frequency (ROCOF) after a frequency event [5]. With increasing penetration of renewable generation and the consequent displacement of traditional synchronous generators (SGs), the overall inertia decreases. The reserve is a crucial issue for sustaining reliability, which ensures the generators' schedules withstand the uncertainty. The system reserves (both upward and downward reserves) could prevent underfrequency load shedding and renewable generation spillage. As renewable generation usually operates at fixed power points for maximum exploitation (maximum power point tracking, MPPT), the system reserves could only be provided by traditional SGs. If the renewable generation reaches a considerable share of the total installed capacity, the traditional plants, which are the only sources of reserves, may not satisfy the reliability criteria [6]. For the Ireland electricity system, the study has shown that more reserves are needed as the penetration level of the wind power increases or the system reliability decreases [7].

Due to direct coupling between mechanical and electric parts in synchronous machines, the inertial response (IR) is naturally provided to suppress ROCOF and mitigate frequency nadir (or peak). Many grid codes have also required inverter-based generation (IBG) to provide IR as an ancillary service [8]. By modifying the supplementary controllers of power electronic interfaces (PEIs) to emulate the external characteristics of traditional SGs, studies have proposed the concept and several approaches for virtual synchronous generator (VSG) algorithms [9-13]. By sensing circuit parameters (instantaneous voltages and currents) and calculating the instantaneous power, the VSG algorithm enables PEIs to mimic the swing equation, which provides instantaneous inertial response (IIR) [9]. Furthermore, the emulation of the speed governor can also be embedded in supplementary control loops to perform primary frequency response (PFR) [14-17]. It is noted that, for PEIs under VSG control, energy headroom in renewable units is a prerequisite during frequency response. The energy could come from the kinetic energy in wind turbines or rotors, the electrostatic energy in capacitors, or the stored energy in accessory equipment [1]. However, the above studies are all restrained in the stages of the short-term frequency response [18]. The frequency control of the conventional power systems includes a hierarchical structure, because the system operation requires the ability to respond to change in demand and supply in multiple temporal stages [19]. With higher penetration of renewable generation, the IBG units would eventually and inevitably take the responsibility of regulating the overall energy balance because of the consequent displacement of traditional SGs. Therefore, the flexibility of the power system operation requires the VSG algorithm to extend its application scope.

The generation units can be divided into two components, the primary energy input, and the electricity generation. The electrical part mainly determines the external characteristics, but it is also restricted by the availability of primary power input. The mechanical power of traditional SGs comes from fossil fuels, hydropower, and nuclear power, which are abundant and fully controllable. On the contrary, renewable resources are time-varying and stochastic. In the view of transmission/distribution system operators (TSO/DSO), the renewable generation is irresponsible and undispatchable [6]. To maintain the overall power balance against unexpected deficits or surpluses, system reserves are indispensable. In some countries, the reserve is quantified as the capacity of the largest generator, which assumes any loss of generation greater than the largest infeed is very infrequent [20]. This reserve quantification method, which focuses on the forced outages of individual plants, is simple, but restrained by rules of thumb. Large-scale renewable integration has challenged this method due to its uncertain nature [20]. The reason for this is that the variations of renewables are continuous, and may be in addition to generator outages caused by discrete events (such as a lightning strike). To deal with this, 
some scholars have proposed reliability-based reserve quantification methods, which determine the reserve requirement based on reliability index, such as loss-of-load probability (LOLP) [7]. The loss of load happens if the power production and upward reserves are not able to compensate for the power deficits caused by the combined uncertainties of the load and renewable generation, as well as the outage of power plants. The renewable generation spillage happens when negative reserves cannot compensate for the surplus power from renewable plants [21]. Furthermore, the reliability-based reserve requirement is integrated with the economic dispatch model to realize joint scheduling of generation and reserve [22,23]. It is noted that, in these approaches, the reserves are scheduled to the synchronous generators only, because the IBG is not schedulable.

In recent research, the predetermined power profile and deloading strategies have been proposed for RG units to participate in power balance regulation. Firstly, the predetermined strategy modifies the power profile of RG units [24,25]. When frequency fluctuations happen, the output of wind turbines is set according to a predesigned curve [26-29]. It is noted that once the predetermined strategy kicks in, the RG output is irrelative to the system frequency. Moreover, this strategy may cause another issue called the second frequency drop (SFD). This is because when the response capability is exhausted, RG units must decrease their output power and restore initial states (such as rotor speed or DC bus voltage) by their own generation capabilities for self-stability, disregarding the actual system frequency conditions. Another strategy is the deloading strategy, which controls the RG unit to operate at a sub-optimum point in the normal conditions [30]. The generation availability is partly curtailed between the maximum power point (MPP) and the suboptimum point, and the output power can be adjusted between such intervals in different time periods. The deloading strategy enables the renewable units to function as long-term power reserves to provide not only PFR, but also secondary frequency regulation (SFR). For example, overspeeding and pitch control can control the power output in a wide range of wind speeds for wind turbines $[30,31]$. However, the opportunity cost is inevitable, because of the loss of a part of the renewable generation availability.

The future power system is represented by RESs and PEIs. The intrinsic differences between traditional SGs and PEI-based RESs lie in both parts of the external characteristics and the power profiles. To solve the incompatibilities while operate economically, this paper presents emulation strategies and economic dispatch for VSG-based RESs participating in multiple temporal stages of system frequency control. The contributions of this work can be summarized as follows:

(1) The VSG algorithm is extended and complemented to enable PEIs to perform multiple temporal stages of frequency control. The emulation control strategies of SFR and TFR are added to perform long-term frequency regulations.

(2) The renewable generation is deloaded to function as long-term active power reserves. The power profiles of the renewable generation units are modified to be homogeneous to those of SGs, in which way the renewable generation could be scheduled as reliable system reserves.

(3) The LOLP and RSP probabilities are presented as reliability criteria. A generation-reserve co-optimized model is built to solve the LOLP-based economic dispatch problem. Through the generation and reserve schemes, it is possible to quantify how much the renewable generation should be deloaded as system reserves at each interval.

The rest of the paper is organized as follows: Section 2 presents the VSG control algorithm that enables the capabilities of multiple temporal stages of frequency control, including IR, PFR, SFR, and TFR. Section 3 demonstrates the LOLP and renewable spillage probability (RSP) indexes for the IBG units in MPPT mode. Section 4 illustrates the modification of the power profile of RG units, which eliminates generation uncertainties according to the properties of Gaussian distribution. The LOLP and RSP when the RG units are calculated under VSG control. Section 5 presents the objective function and constraints of the proposed economic dispatch approach. Section 6 shows the simulation results of the proposed extended VSG algorithm and the case study of the economic dispatch approach. 


\section{VSG-Based Frequency Control}

The system frequency indicates the overall power balance regulation between the generation and the consumption at any instantaneous time. In the traditional SG-dominated power system, the active power-frequency control is a series of multiple temporal stages, which can be divided into four parts [32], as shown in Table 1.

Table 1. Conventional multiple temporal frequency control.

\begin{tabular}{ccccc}
\hline & IR & PFR & SFR & TFR \\
\hline Time scale & Instantaneous & Seconds-30 s & 10-30 min & Hours-day ahead \\
\hline Activation & ROCOF & $\begin{array}{c}\text { Frequency deviation crosses } \\
\text { a preset deadband }\end{array}$ & $\begin{array}{c}\text { Frequency deviation last } \\
\text { over a preset period }\end{array}$ & Economic dispatching \\
\hline Reference & Naturally provided & Frequency deviation & Frequency deviation & Load reference \\
\hline Control parameter & $H$ & $R_{S G}$ & $K_{I}$ & $P_{\text {scheduled }}$ \\
\hline Participants & All SGs & All SGs with headroom & Selected SG unit & All SGs \\
\hline Executor & Rotating equipment & Speed governor & Turbine \\
\hline Energy resource & Kinetic & Primary input & Primary input \\
\hline Restoration & The restoration of rotor speed is coupled with the frequency recovery of the system. &
\end{tabular}

The concept of VSG is to mimic the dynamic properties of SGs to let both behave with approximately synchronous responses to load changes. Therefore, the emulations of virtual inertia and the virtual speed governor are indispensable. For PEI-based renewable generation, the external characteristics are largely determined by the supplementary controller. In inchoate studies, among the VSG implementations in different orders, the simplest second-order model is with better stability in transients [33] and can be combined with virtually any VSI control strategies based on a cascade structure [34]. By the modification of the supplementary controller, the VSG algorithm enables the PEIs to function in the same way as SGs with the capability to perform frequency response and frequency regulation in multiple temporal stages.

\subsection{Emulation of IR and PFR}

The inertial response of the SGs is instantaneous, and without prerequisite measurements. For traditional SGs, the inertia is provided by the kinetic energy stored in the rotation equipment. The inertia constant $H_{S G}$ indicates the inertia property, which can be expressed as

$$
H_{S G}=\frac{J_{S G} \omega_{r}^{2}}{2 V A_{\text {base }}}
$$

where $J_{S G}$ is the moment of inertia, $\omega_{r}$ is the angular speed of the rotor, $V A_{\text {base }}$ is the rated power. Similar to $H_{S G}$, the virtual inertia constant $H_{\text {vir }}$ of PEIs can be expressed as the ratio of the provided energy to the rated power.

$$
H_{\text {vir }}=\frac{J_{\text {vir }} \omega_{m}^{2}}{2 V A_{\text {base }}}
$$

where $J_{\text {vir }}$ is the virtual moment of inertia, $\omega_{m}$ is the virtual angular speed.

The inertial response follows Newton's law of motion, which can be expressed as the swing equation

$$
P_{m}-P_{e}=\frac{d \Delta \omega_{r} / d t}{2 H_{S G}}+D \Delta \omega_{r}
$$


where $D$ is the damping coefficient of frequency sensitive load, $P_{m}$ and $P_{e}$ are the virtual mechanical and electrical power, $\omega_{r}$ is virtual angular speed. When the swing equation is represented by the inertia constant, all the parameters are per-unit values. Then the inertia support can be expressed as

$$
\Delta P_{I R}=-2 H_{\text {vir }} \frac{d \Delta f}{d f}
$$

The PFR of SGs is provided by the turbine-governor system. In per unit value, the droop property for an SG with a typical reheat steam turbine is

$$
\Delta Y=-\frac{1}{R} \times \frac{1}{1+s T_{G}} \times \frac{1+s F_{H P} T_{R H}}{\left(1+s T_{C H}\right)\left(1+s T_{R H}\right)}
$$

where $R$ is speed droop, $Y$ is the valve position, $F_{H P}, T_{C H}$, and $T_{R H}$ are typical parameters for a reheat steam turbine. The emulation for the properties of turbines of SGs is necessary when the VSG-based PEIs are operated in parallel with traditional power plants. In steady state, the supporting power by PFR is

$$
\triangle P_{P F R}=-\frac{1}{R} \Delta f
$$

The implementation of the emulation control strategies for IR and PFR is executed based on the mathematical model of SGs mentioned before. When the VSG algorithm is activated, the control block of the angular speed deviation is shown in Figure 1.

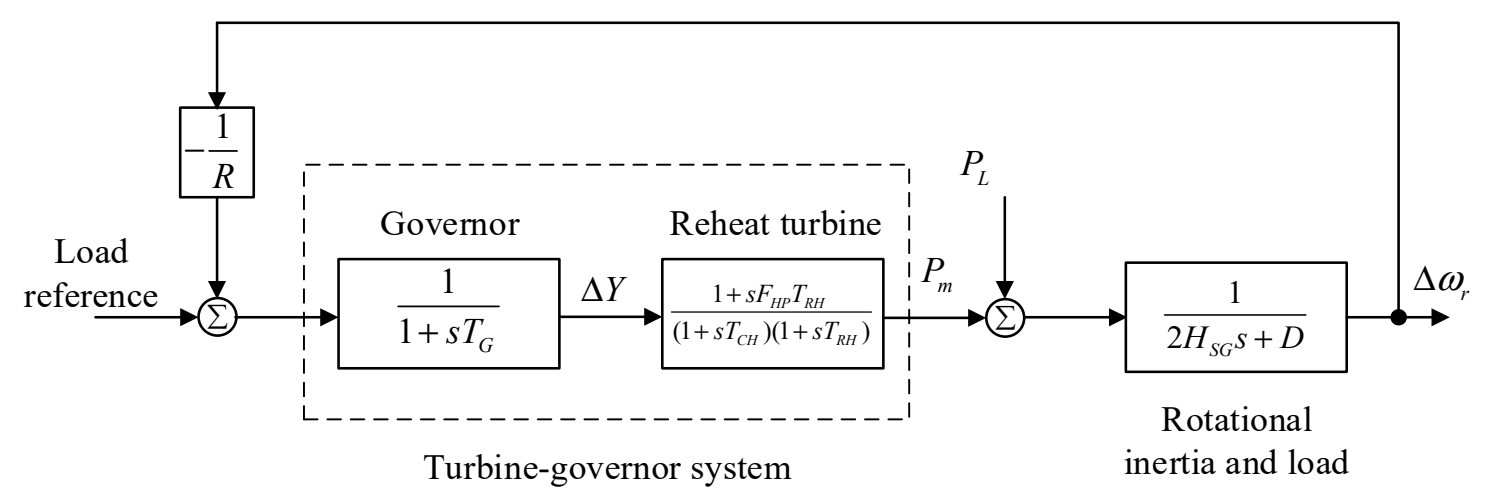

(a) IR and PFR control in SGs

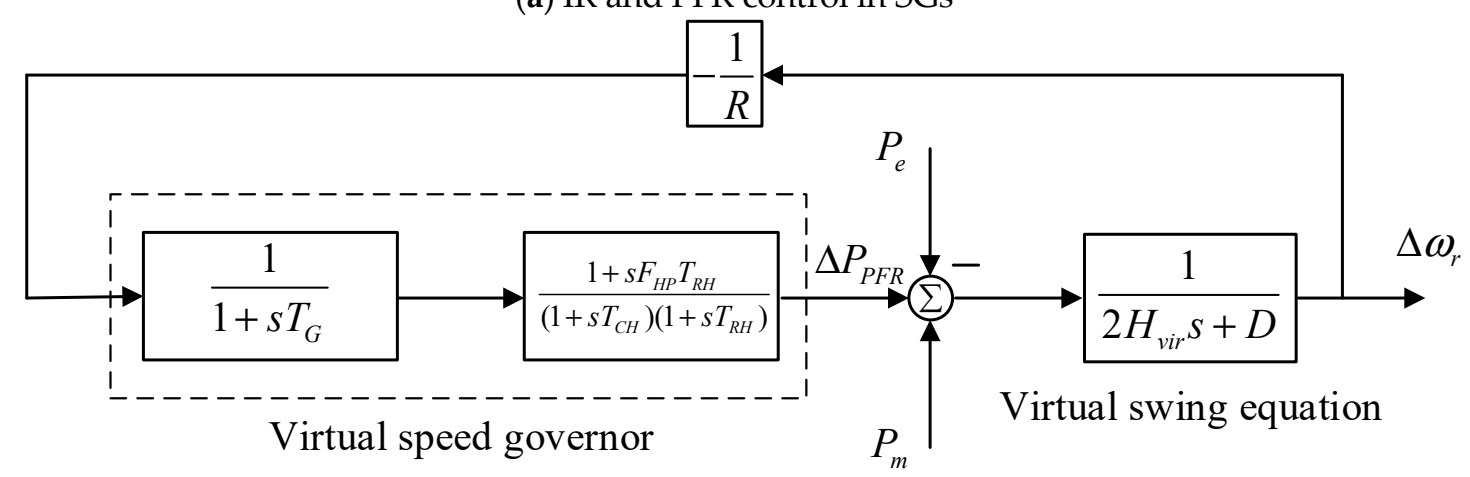

(b) IR and PFR emulation in VSG

Figure 1. Block diagram of IR and PFR in (a) SG, (b) VSG.

\subsection{Emulation of SFR}

For traditional SGs, the SFR is executed by the regulation of load reference settings, which is shown in Figure 2a. In the block diagram for SGs, the signal of the load reference also passes through the blocks of the turbine-governor system. However, as only specific units in a power system are 
selected to perform AGC regulation, when the emulation of AGC is implemented on VSG-PEIs, the load reference can be directly fed into the block of the virtual swing equation, as shown in Figure $2 \mathrm{~b}$. In Figure $2 b, \tau$ is the time delay of $S F R$, and $K_{i}$ is the coefficients of the integral controller.

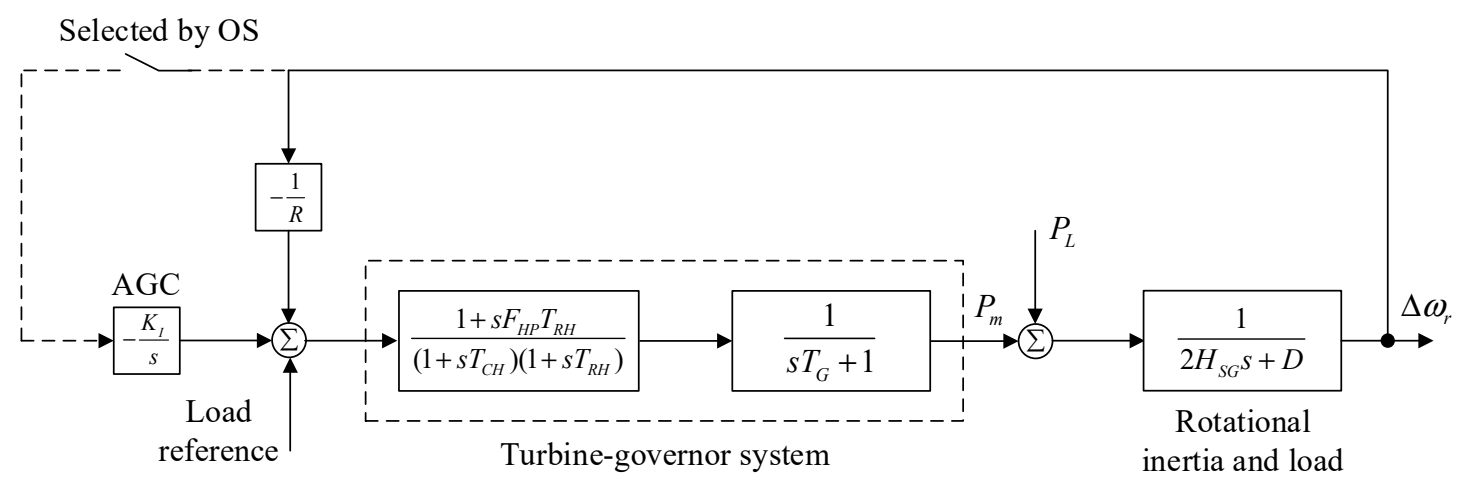

(a) AGC on synchronous generators

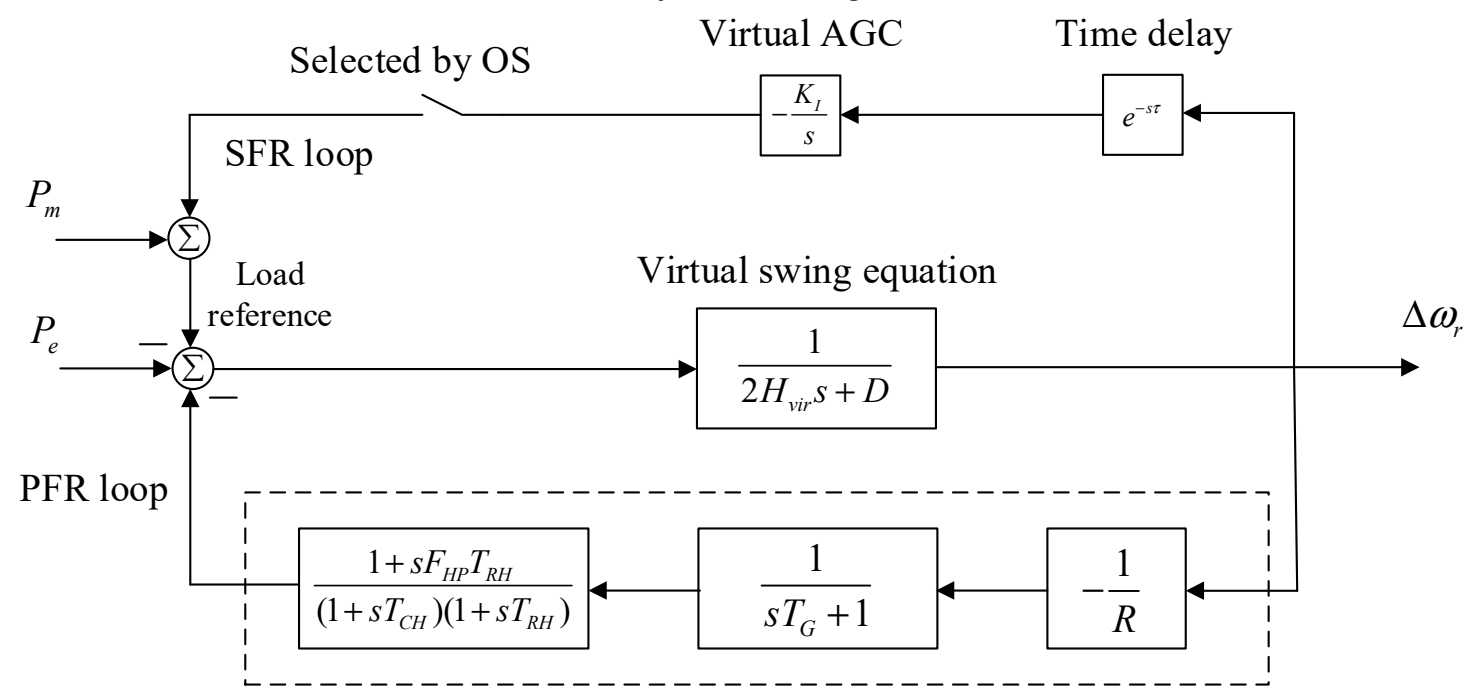

Virtual turbine-speed governor

(b) Virtual AGC on VSG-PEIs

Figure 2. Block diagram of SFR.

\subsection{Emulation of TFR}

In the conventional power system, the tertiary control is the optimal allocation of generation resources to handle present and future fluctuations in generation and load. The time span of the tertiary control varies from hours to day-ahead. The TFR is executed by regulating the settings of load reference on each generator. The implementation of TFR is shown in Figure 3. 


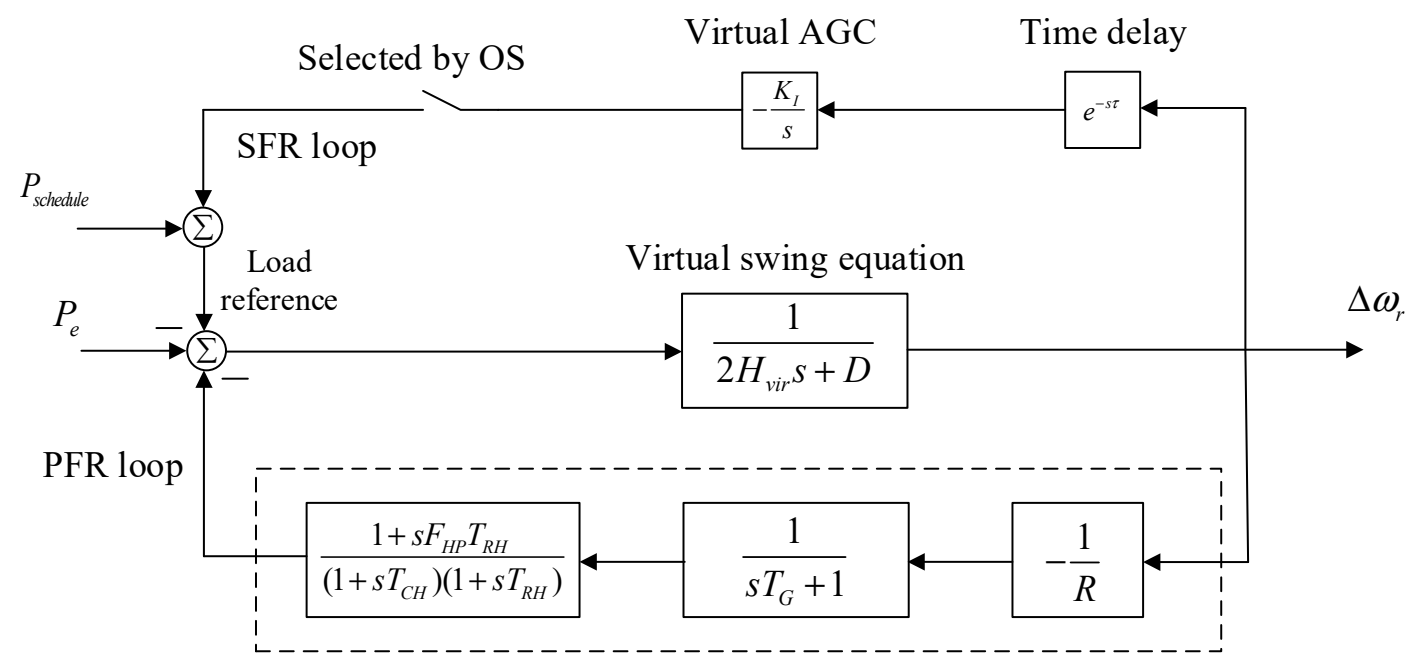

Virtual turbine-speed governor

Figure 3. Implementation of TFR.

\section{Reliability Criteria for IBG Units in MPPT Mode}

When IBG under MPPT control does not participate in frequency regulation, the uncertainties of the renewable generation and load are two critical factors related to reserve determination. Since the distribution of their prediction errors does not affect the proposed method, for simplicity, it can be assumed that the prediction errors obey a zero-mean Gaussian distribution. At the time period $t$, the forecast error of RG is denoted by $\Delta P_{t}^{R}$, of which the probability density function is $f\left(\Delta P_{t}^{R}\right) \sim N\left(0, r_{t}^{2}\right)$. Similarly, the forecast error of demand is denoted by $\Delta P_{t}^{D}$, of which the probability density function is $f\left(\Delta P_{t}^{D}\right) \sim N\left(0, d_{t}^{2}\right)$. Furthermore, the net load forecast error can be defined as $\Delta P_{t}^{N}$, which is defined as:

$$
\Delta P_{t}^{N}=\Delta P_{t}^{D}-\Delta P_{t}^{R}
$$

of which the probability density function is $f\left(\Delta P_{t}^{N}\right) \sim N\left(0, r_{t}^{2}+d_{t}^{2}\right)$, since renewable generation and load are independent of each other. It is noted that for a power system with zero penetration of renewables, the net load forecast error only contains the error from the demand forecast. Additionally, the forced outage rate (FOR) of traditional generators is denoted by $p^{F O}$.

In this paper, the forecast error of the renewable generation and the demand, as well as the outage of traditional generators, are three factors that cause frequency events that lead to load shedding or renewable spillage incidents. Therefore, two indexes, LOLP and RSP, are proposed as two reliability criteria to evaluate the system.

The frequency of the power system is directly coupled with the power balance between generation and demand. The under-frequency event may happen when the generation cannot meet the demand. Since the probability of outage of two or more generators is very low [35], in this paper, the scenarios of no generation outage and single generator outage are considered. The LOLP at a specific period $t$ is denoted by $p_{t}^{L O L P}$, which can be expressed as:

$$
\begin{aligned}
& p_{t}^{L O L P}=\prod_{i=1}^{N}\left(1-p_{i}^{F O}\right) \cdot p\left\{\left(\Delta P_{t}^{N}-R_{t}^{u}\right)>0\right\}+ \\
& \sum_{i=1}^{N} p_{i}^{F O} \cdot \prod_{\substack{j=1 \\
j \neq i}}^{N}\left(1-p_{j}^{F O}\right) \cdot p\left\{\left(\Delta P_{t}^{N}+P_{i}^{M A X}-R_{t}^{u}\right)>0\right\} \\
& j=1
\end{aligned}
$$

where $N$ is the number of SGs, $R_{t}^{u}$ is the upward reserve at period $t, P_{i}^{M A X}$ is the upper output limit of generator $i$. 
Over-frequency events may happen when the generation exceeds the demand, which the downward reserve is unable to compensate. The calculation of RSP in period $t$ is denoted by $p_{t}^{R S P}$, which can be expressed by

$$
p_{t}^{R S P}=p\left\{\left(\Delta P_{t}^{N}+R_{t}^{d}\right)<0\right\}
$$

where $R_{t}^{d}$ is the downward reserve at period $t$. If the rated LOLP and RSP are denoted by $p_{\text {rated }}^{L O L P}$ and $p_{\text {rated }}^{\text {RSP }}$, then the reliability constraints can be expressed as:

$$
\begin{gathered}
p_{t}^{L O L P} \leq p_{\text {rated }}^{\text {LOLP }} \\
p_{t}^{\text {RSP }} \leq p_{\text {rated }}^{\text {RSP }}
\end{gathered}
$$

The values of $p_{\text {rated }}^{L O L P}$ and $p_{\text {rated }}^{R S P}$ are set by the dispatch system operators, which are usually between 0 and 0.05 . The solutions of the upward and downward reserve $R_{t}^{u}$ and $R_{t}^{d}$ satisfying the desired reliability criteria can be found by searching the LOLP and RSP solution spaces, respectively.

\section{Reliability Criteria for IBG Units in VSG Mode}

As the conventional power system is undergoing an evolving transition to a converter-dominated regime, IBG in the future grid will inevitably take the role (regulating the overall energy balance for stability and reliability) of SGs. For the process of electricity generation, every generation unit includes two components: the primary energy input, and electric power generation, as shown in Figure 4.

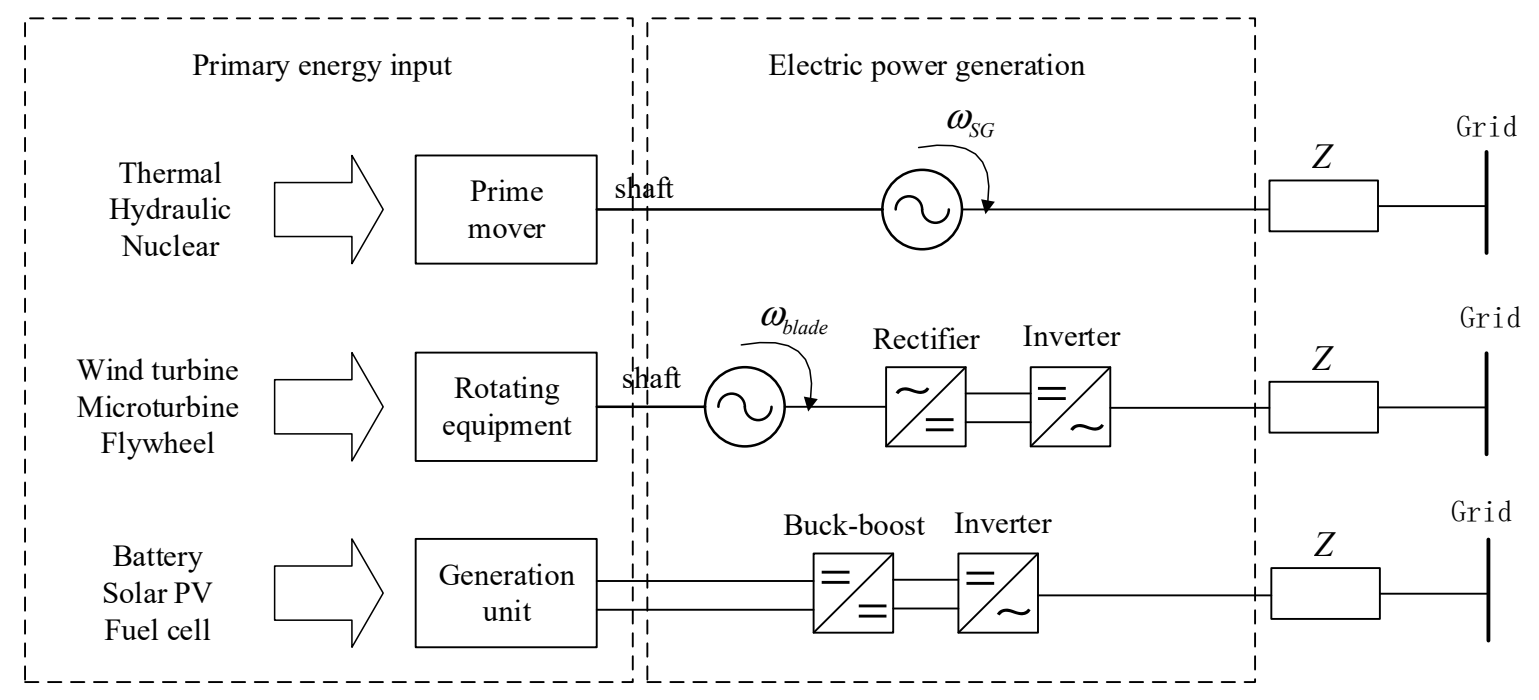

Figure 4. Comparison between SGs and IBG.

If VSG-IBG units participate in secondary and tertiary frequency regulations, persistent power reserves for power increment and decrement counteracting frequency deviations are indispensable. In other words, the capabilities of frequency regulation are determined by the availability of the reserved power input. For renewable energy sources alone (regardless of energy storage accessories), the reserved energy comes from curtailable generation ability. Generally, active power reserves using RG units can be realized through two types of control strategies: (1) the delta control, which deloads RG units by constant percentages or values [36], and (2) the balance control, which controls the RG output through an upper limit [37]. The reserves by the delta control are still stochastic on the basis of meteorological conditions. It is noted that the decisive difference in the primary input between the SGs and the RG units is whether the primary power is dispatchable or stochastic. Inspired by this, in this paper, the uncertainty of renewable generation is eliminated based on a deloading strategy with fixed upper limits. The principle of deloading control with fixed upper limits is shown in Figure 5. 


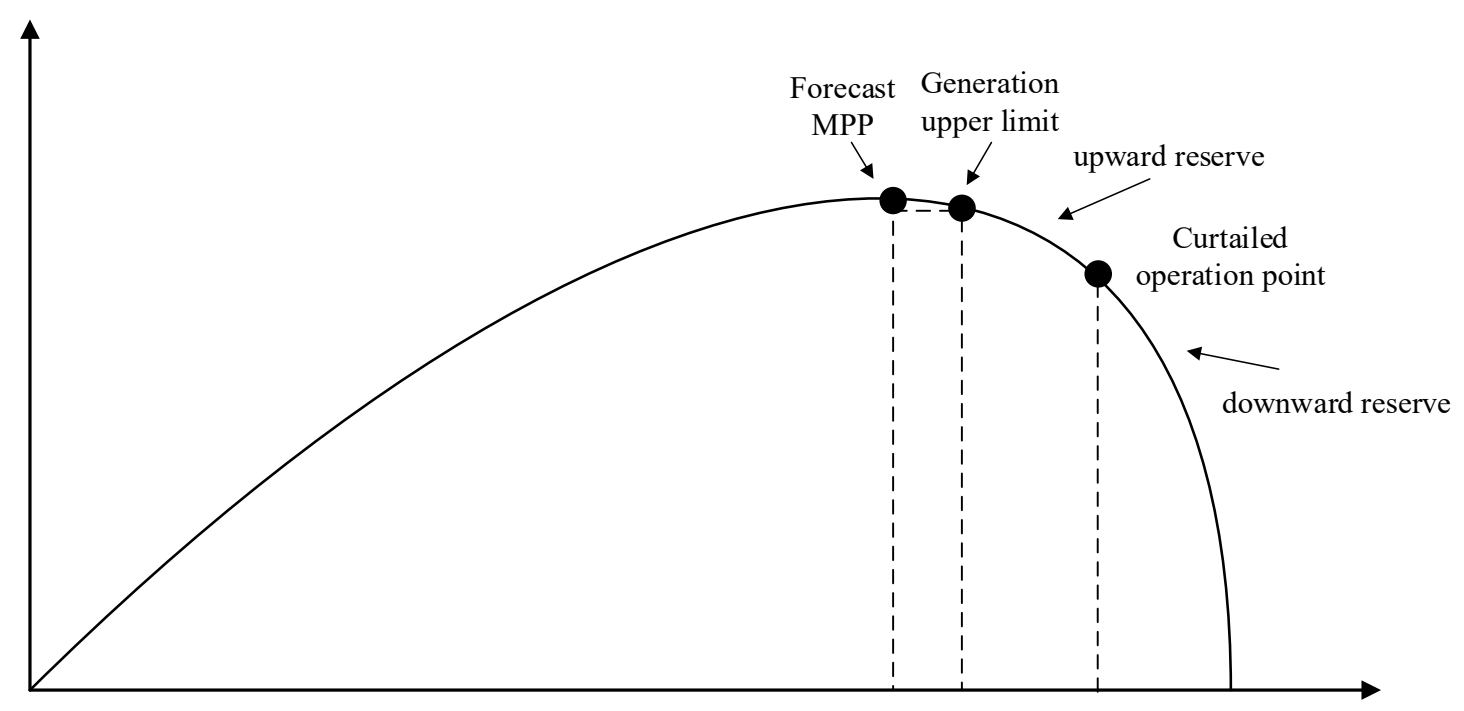

Figure 5. Curtailed IBG with fixed upper generation limit.

As the forecast error of RG obeys Gaussian distribution, RG output also obeys Gaussian distribution, whereby the probability density function is $f\left(P_{t}^{R}\right) \sim N\left(P_{t}^{F R}, r_{t}^{2}\right)$. The upper output limit of renewable generation unit can be set as

$$
P_{t, \max }^{R}=P_{t}^{F}-3 r_{t}
$$

which is shown in Figure 6.

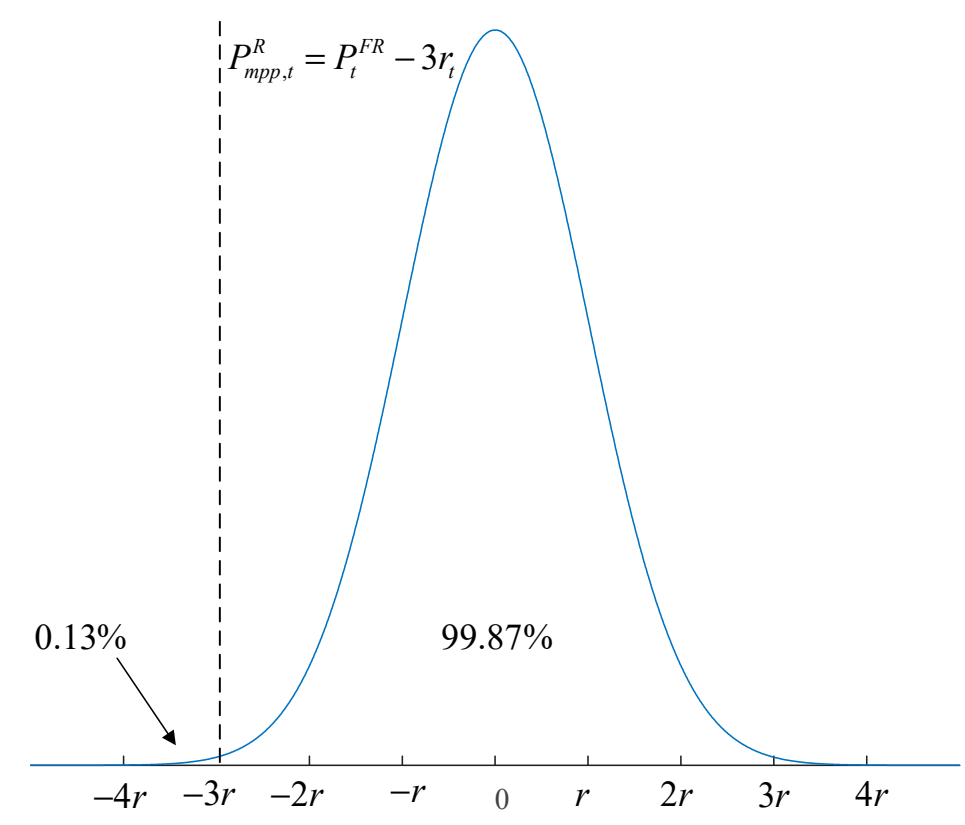

Figure 6. Probability density function of renewable generation.

In this way, the property of the generation profile of IBG is modified with fixed upper limits, and the generation uncertainties of the RG units could be eliminated. Consequently, after the transformation, the uncertainty mainly lies in the load disturbances, and the net load forecast error is

$$
\Delta P_{t}^{N}=\Delta P_{t}^{D}
$$


The LOLP for a specific period $t$ in power system with grid-supporting IBG can be expressed as

$$
\begin{aligned}
& p_{t}^{L O L P}=\prod_{i=1}^{N}\left(1-p_{i}^{F O}\right) \cdot p\left\{\left(\Delta P_{t}^{N}-R_{t}^{u}\right)>0\right\}+ \\
& \sum_{i=1}^{N} p_{i}^{F O} \cdot \prod_{\substack{j=1 \\
j \neq i}}^{N}\left(1-p_{j}^{F O}\right) \cdot p\left\{\left(\Delta P_{t}^{N}+P_{i}^{M A X}-R_{t}^{u}\right)>0\right\}
\end{aligned}
$$

where $N$ is the number of generation units, including traditional generators and VSG-IBG units. Renewable generation spillage probability in period $t$ can be expressed as

$$
p_{t}^{R S P}=p\left\{\left(\Delta P_{t}^{N}+R_{t}^{d}\right)<0\right\}
$$

where $R_{t}^{d}$ is the downward reserve at period $t$, which is provided by both SGs and VSG-IBG.

Since the RG unit has been modified with a fixed upper output limit at each time period, the SGs and RG are homogeneous in power profile. Therefore, the RG unit could be seen as a virtual SG-based plant, and the economic dispatch including VSG-IBG could be solved.

\section{Generation-Reserve Co-Optimization Model}

For joint economic dispatch of generation and reserve, a co-optimization dispatch model is built that contains the objective function and a set of constraints.

\subsection{Objective Function}

The objective is to minimize the total operation cost, which involves the generation and reserve cost. The function of the generation cost of SGs is typically expressed as a quadratic function, which can be expressed as

$$
f_{C_{i}}\left(P_{i, t}^{G}\right)=c_{2, i}\left(P_{i, t}^{G}\right)^{2}+c_{1, i} P_{i, t}^{G}+c_{0, i}
$$

where $P_{i, t}^{G}$ is the load of generator $i$ at period $t$; and $c_{2}, c_{1}$, and $c_{0}$ are cost coefficients. The total generation $\operatorname{cost} C_{1, t}$ is the accumulation of the generation cost of all the generators at period $t$, which can be expressed as

$$
C_{1, t}=\sum_{i=1}^{N} f_{C_{i}}\left(P_{i, t}^{G}\right)
$$

For RG units, since they do not consume fossil fuels, the cost coefficients are assumed to be zero. The reserve cost function for SGs can be expressed as a linear equation

$$
f\left(r_{i, t}^{u}, r_{i, t}^{d}\right)=c_{i}^{u} r_{i, t}^{u}+c_{i}^{d} r_{i, t}^{d}
$$

where $r_{i, t}^{u}$ and $r_{i, t}^{d}$ are the upward and downward reserves provided by generator $i$ at period $t$, and $c_{i}^{u}$ and $c_{i}^{d}$ are cost coefficients, correspondingly. The total reserve $\operatorname{cost} C_{2, t}$ is the accumulation of the reserve cost of all the generators at period $t$, which can be expressed as

$$
C_{2, t}=\sum_{i=1}^{N} f_{C}\left(r_{i, t}^{u}, r_{i, t}^{d}\right)
$$

For the VSG-RG units, since the reserves are based on the deloading strategy, which incurs opportunity cost in normal operation, the coefficients are assumed to be close to those of traditional SGs. 
By the combination of generation and reserve cost, the objective function can be expressed as:

$$
\min \sum_{t=1}^{T}\left(C_{1, t}+C_{2, t}\right)
$$

where $T$ is the number of dispatch periods.

\subsection{Constraints}

(1) Power balance constraints.

At any time period $t$, the generation should cater for the demand, and the power balance constraints can be expressed as

$$
\sum_{i \in G} P_{i, t}^{G}+\sum_{j \in R} P_{j, t}^{R}=\sum_{k \in D} P_{k, t}^{D}
$$

where $G, R$, and $D$ are the set of SGs, RG, and load, respectively.

(2) Output margin constraints.

At any time period $t$, the load of generators cannot cross their upper and lower output limits, which can be expressed as

$$
P_{\min , i}^{G} \leq P_{i, t}^{G} \leq P_{\max , i}^{G}
$$

where $P_{\min , i}^{G}$ and $P_{\max , i}^{G}$ are the minimum and maximum capacities of generator $i$. Furthermore, considering its provided reserve, the load of each generator cannot cross its upper and lower limits, either, which can be expressed as

$$
\begin{aligned}
& P_{\min , i}^{G} \leq P_{i, t}^{G}+r_{i, t}^{u} \leq P_{\max , i}^{G} \\
& P_{\min , i}^{G} \leq P_{i, t}^{G}-r_{i, t}^{d} \leq P_{\max , i}^{G}
\end{aligned}
$$

The output of the grid-supporting IBG units also satisfies these constraints.

(3) Ramp constraints.

For the transition of power output in adjacent periods, the ramp constraints can be expressed as

$$
-P_{\text {ramp }, i}^{d} \Delta T \leq P_{i, t+1}^{G}-P_{i, t}^{G} \leq P_{\text {ramp }, i}^{u} \Delta T
$$

where $P_{r a m p, i}^{u}$ and $P_{r a m p, i}^{d}$ are the upward and downward ramp rate of generator $i$, respectively. $\Delta T$ is the dispatch interval. For the reserve, it needs to be dispatched within a preset time. Therefore, the ramp constraints for reserves can be expressed as

$$
\begin{aligned}
& r_{i, t}^{u} \leq P_{\text {ramp }, i}^{u} T_{r} \\
& r_{i, t}^{d} \leq P_{\text {ramp }, i}^{d} T_{r}
\end{aligned}
$$

where $T_{r}$ is the reserve dispatch interval. For the IBG units, since the control of PEIs is fast and accurate, the ramp rate is set to be infinite.

(4) Reserve constraints.

At any time period $t$, the total reserves in the system must meet the reserve requirement according to the rated LOLP and RSP criteria. Therefore, the accumulation of the upward and downward reserves satisfies

$$
R_{t}^{u} \leq \sum_{i=1}^{N} r_{i, t}^{u}
$$




$$
R_{t}^{d} \leq \sum_{i=1}^{N} r_{i, t}^{d}
$$

where $R_{t}^{u}$ and $R_{t}^{d}$ are reserve requirements under preset LOLP and RSP reliability criteria. Furthermore, considering the outage of a single unit, the reserve constraints satisfying the $N-1$ scenario can be expressed as

$$
\forall i \in N \text {, it satisfies }\left\{\begin{array}{c}
R_{t}^{u} \leq \sum_{\substack{j=1 \\
j \neq i}}^{N} r_{j, t}^{u} \\
R_{t}^{d} \leq \sum_{\substack{j=1 \\
j \neq i}}^{N} r_{j, t}^{d}
\end{array}\right.
$$

\section{Simulation and Case Study}

\subsection{Simulation of Multiple Temporal Stages of Frequency Control}

The proposed VSG algorithm involves the emulation of IR, PFR, SFR, and TFR. The power rating is scaled down to $1.5 \mathrm{kVA}$ to verify the proposed algorithm. The simulation in this section involves the parameters in Table 2.

Table 2. Parameters in simulation.

\begin{tabular}{cccccc}
\hline Parameter & Value & Unit & Parameter & Value & Unit \\
\hline$V_{d c}$ & 800 & $\mathrm{~V}$ & $H$ & 5 & $\mathrm{pu}$ \\
$V_{a c}$ & 0.22 & $\mathrm{kV}$ & $D$ & 1 & $\mathrm{pu}$ \\
$L$ & 10 & $\mathrm{mH}$ & Percentage $R$ & 5 & $\mathrm{pu}$ \\
$C$ & 350 & $\mu \mathrm{F}$ & Voltage droop & $3 \%$ & $\mathrm{pu}$ \\
$f$ & 50 & $\mathrm{~Hz}$ & $\tau$ & 20 & $\mathrm{~s}$ \\
$f_{\text {pwm }}$ & 5000 & $\mathrm{~Hz}$ & Load step & 0.05 & $\mathrm{pu}$ \\
$\mathrm{VA}_{\text {base }}$ & 15,000 & $\mathrm{~W}$ & $K_{I}$ & 10 & - \\
\hline
\end{tabular}

\subsubsection{Simulation of IR and PFR}

The IR and PFR for a step increase of load $(0.05 \mathrm{pu})$ at $1 \mathrm{~s}$ is shown in Figure 7. 


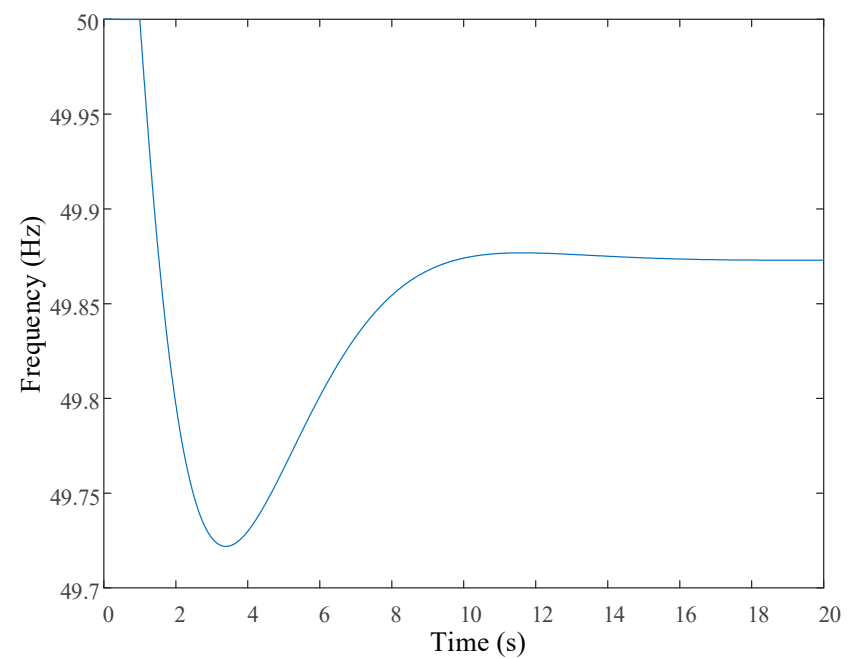

(a) system frequency

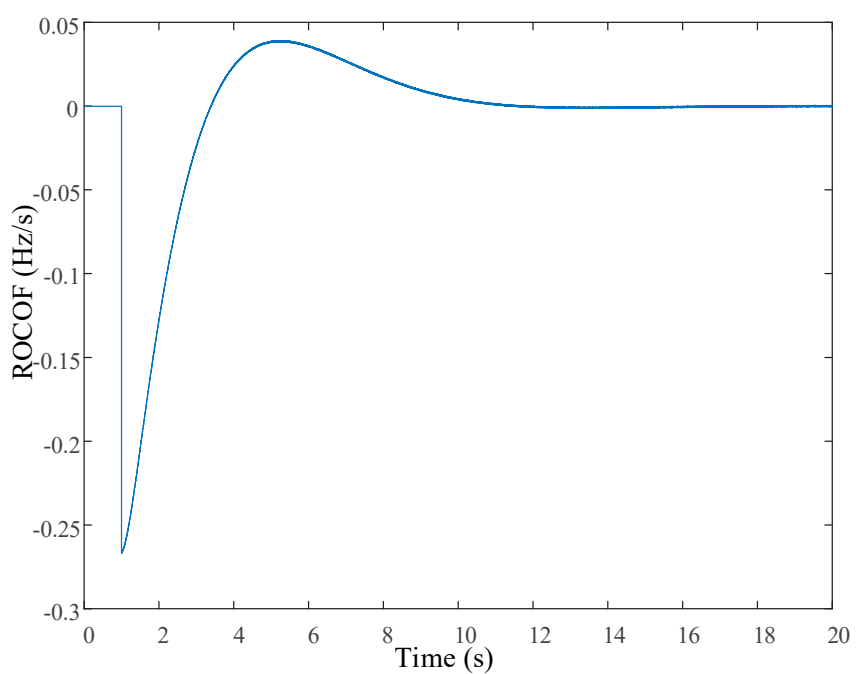

(b) $\mathrm{ROCOF}$

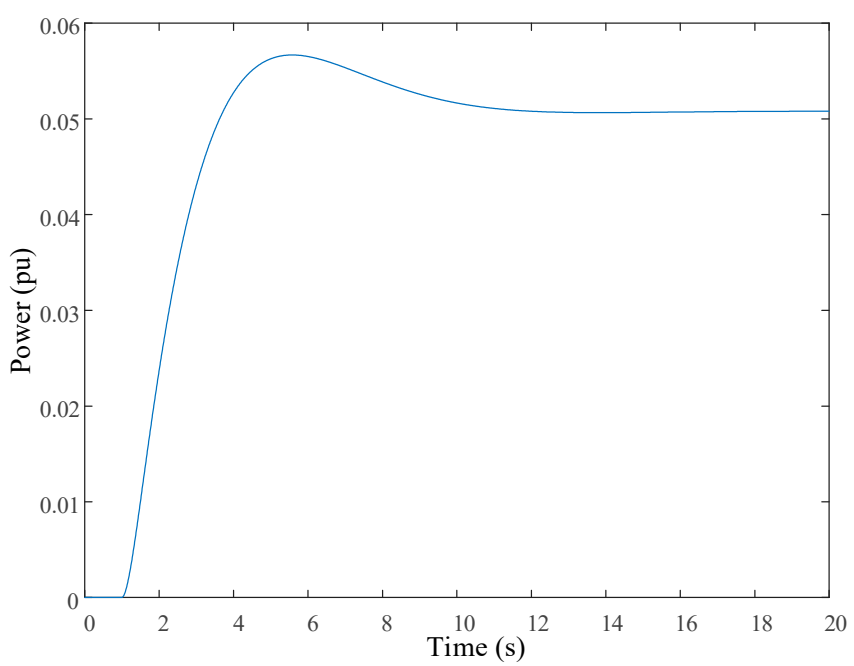

(c) power increment in PFR loop

Figure 7. Simulation of IR and PFR. 
From Figure 7, compared to the response of grid-supporting VSI, the peak time (at which the nadir is reached) is delayed by the inertia effect. The power increment in the PFR loop gradually and partially restores the frequency. Consequently, the emulation of the characteristics of the composite frequency response of SGs is achieved.

\subsubsection{Simulation of SFR}

The SFR for the same load step change is shown in Figure 8. The SFR kicks in after the frequency deviation lasting for $20 \mathrm{~s}$.

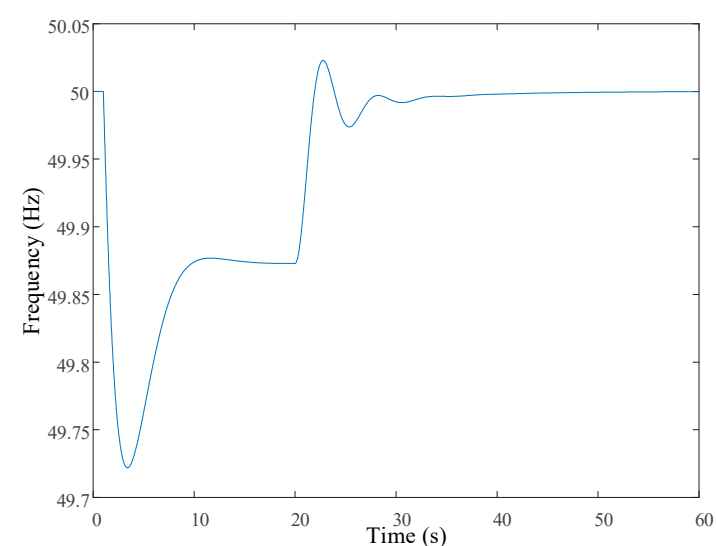

(a) system frequency

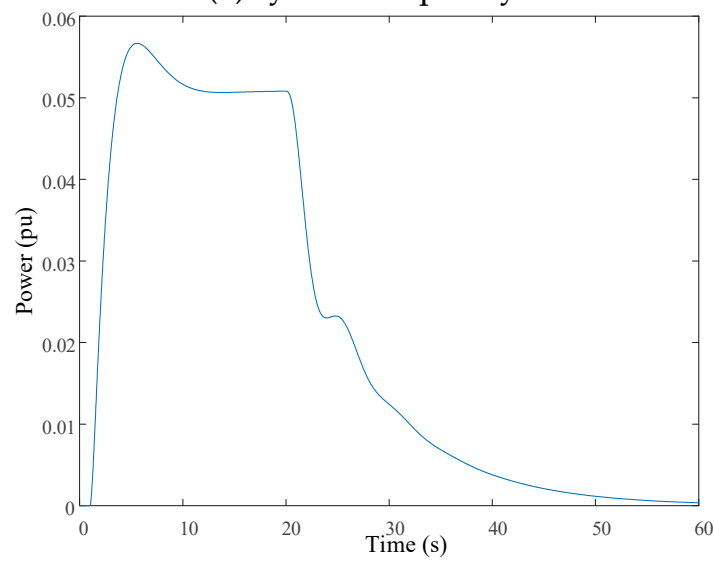

(c) power increment in PFR loop

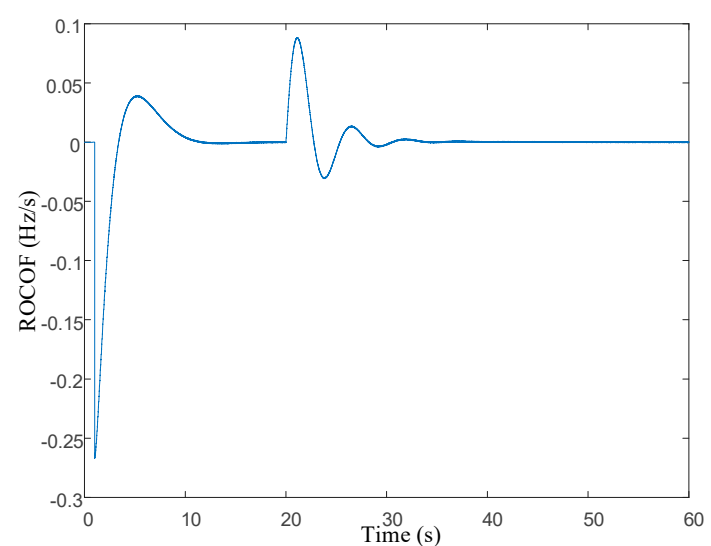

(b) ROCOF

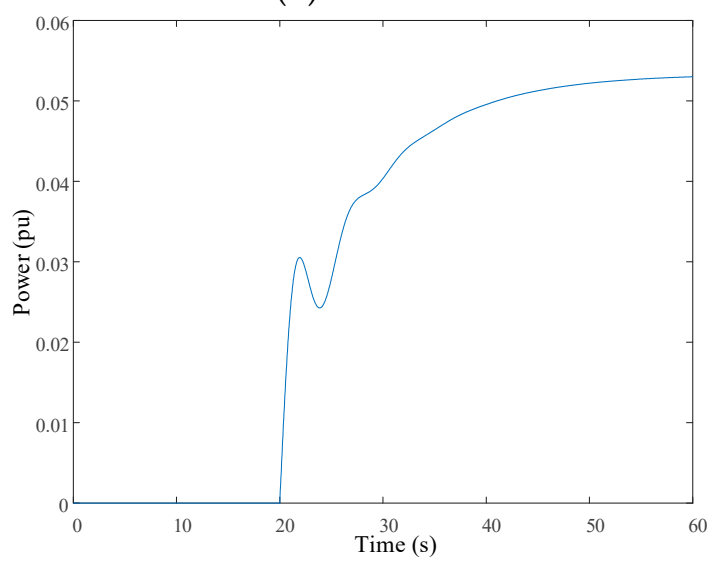

(d) power increment in SFR loop

Figure 8. Simulation of SFR for a step change of load.

From Figure 8, the SFR is activated after the PFR has stabilized the system frequency. When SFR kicks in, the load reference settings of selected SGs are regulated. The system frequency is gradually restored. The power increment of PFR is overridden by the power increment from the SFR loop.

\subsubsection{Simulation of TFR}

The uncertainty in the power system includes the load forecast error, the renewable generation forecast error, and the outage of SGs. As a result, in each schedule interval, for a specific load reference setting, there is a tiny gap between the generation and the demand. Then the power imbalance is compensated through the process of IR, PFR, and SFR. When the load increase is $3 \%$ higher than the change of load reference, the dynamic responses of frequency control are shown in Figure 9. 


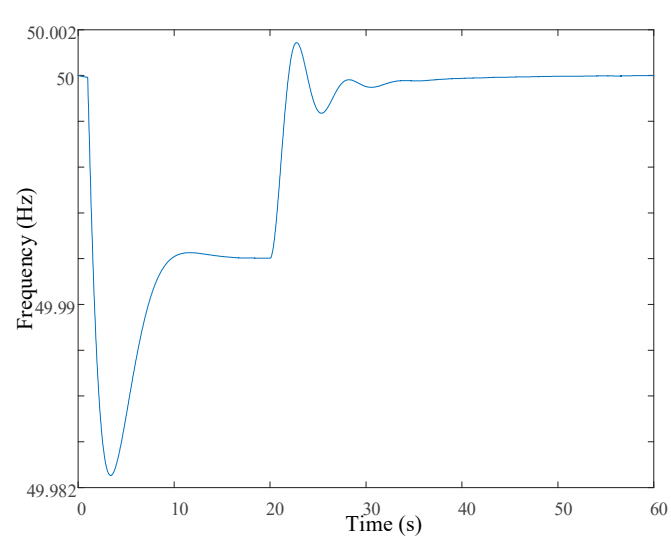

(a) system frequency

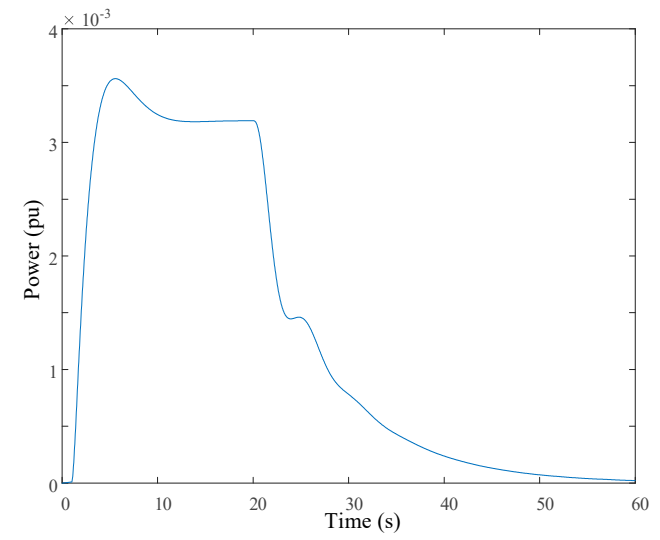

(c) power increment of PFR loop

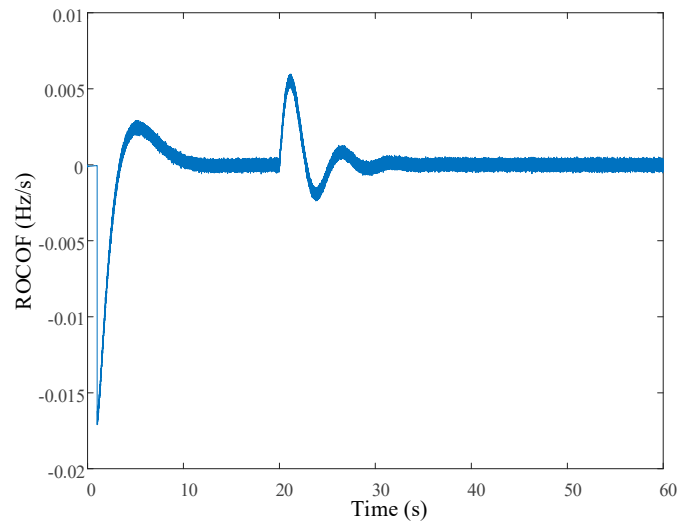

(b) $\mathrm{ROCOF}$

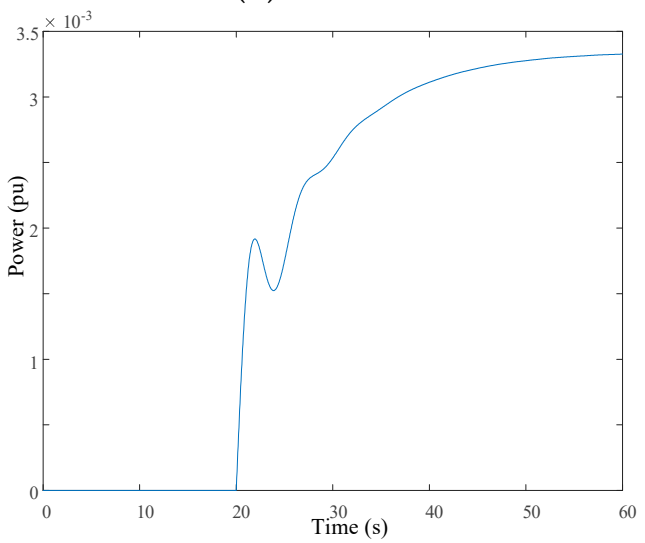

(d) power increment of SFR loop

Figure 9. Simulation of load forecast gap in TFR.

\subsubsection{Summary}

The control of system frequency provided by PEIs under VSG control is shown in Figure 10. The VSG algorithm enables IBG units to perform multiple temporal frequency control after a frequent event.

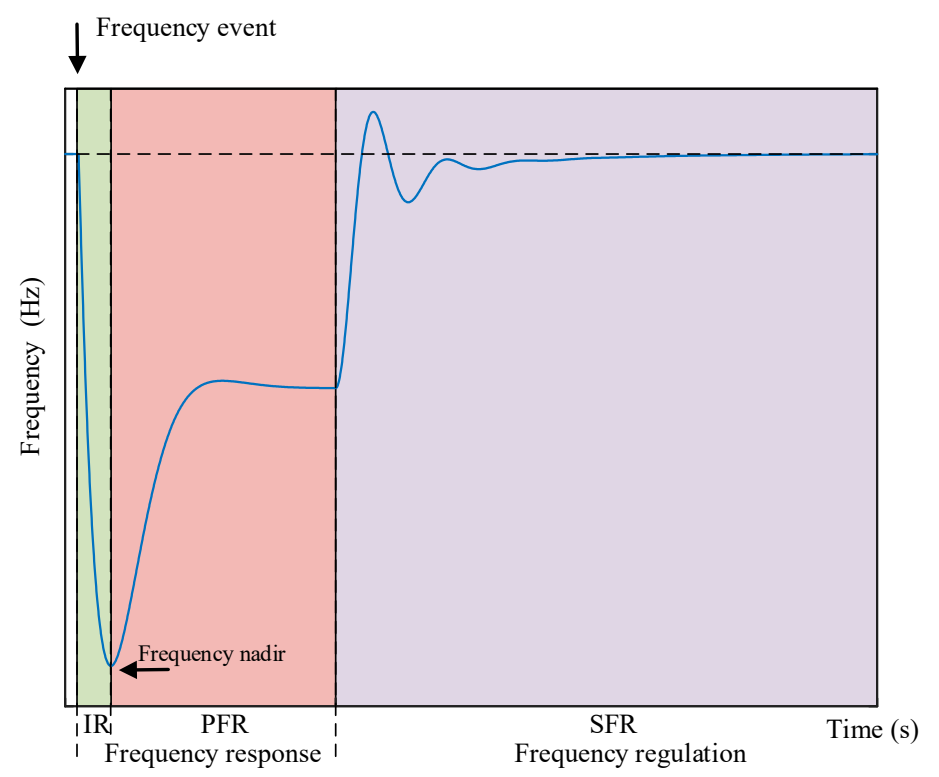

Figure 10. Multiple temporal frequency control under VSG algorithm. 
Correspondingly, the multiple temporal stages of frequency control provided by VSG emulation strategies are summarized in Table 3.

Table 3. Multiple temporal stages of frequency control of VSG-Based PEIs.

\begin{tabular}{ccccc}
\hline & IIR & PFR & SFR & TFR \\
\hline Time scale & Less than $1 \mathrm{~s}$ & seconds & Seconds to Mins & Hours-day ahead \\
\hline Activation & ROCOF & $\begin{array}{c}\text { Frequency deviation } \\
\text { crosses preset deadband }\end{array}$ & $\begin{array}{c}\text { Frequency deviation last } \\
\text { over a preset period }\end{array}$ & $\begin{array}{c}\text { Optimization } \\
\text { algorithms }\end{array}$ \\
\hline Reference & ROCOF & Frequency deviation & Frequency deviation & Load reference \\
\hline Control parameter & $M$ & $R$ & $K_{I}$ & $P_{\text {reference }}$ \\
\hline Participants & VSG-PEIs & VSG-PEIs & Dispatchable IBG & Dispatchable IBG \\
\hline Executor & Virtual inertia & Virtual speed governor & Virtual AGC & System operator \\
\hline Energy source & \multicolumn{2}{c}{ Kinetic, electrostatic, or chemical, storage, deloading renewable sources } \\
\hline Restoration & The restoration of virtual rotor speed is coupling with the frequency recovery of the system \\
\hline
\end{tabular}

\subsection{Case Study for Generation and Reserve Schemes}

The proposed approach is tested in two scenarios of RG under MPPT and VSG mode. The economic dispatch model is programmed in MATLAB and solved by Gurobi. Based on the original six-bus three-generator system [38], a renewable unit is added, which is shown in Figure 11. In VSG mode, the RG is denoted as generation unit 4 . The system is tested for economic dispatching with six horizons.

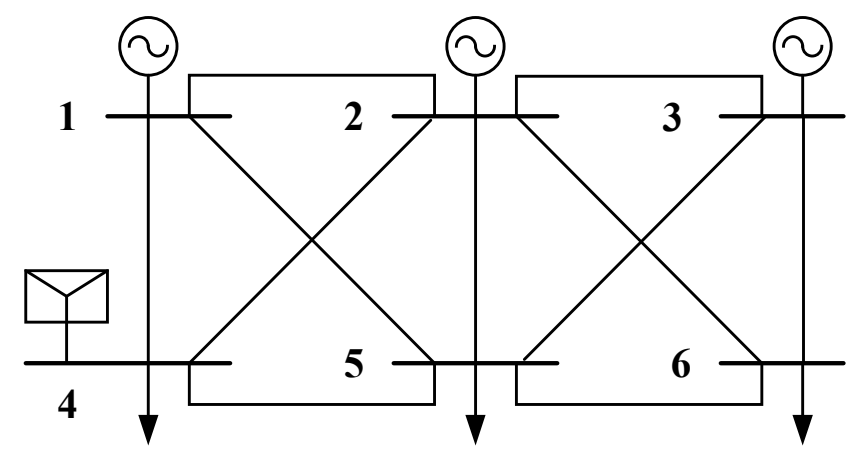

Figure 11. Generation scheme of SGs when the IBG is in VSG or MPPT mode.

The predicted renewable generation and load, as well as the upper limit of RG in VSG mode, are shown in Table 4.

Table 4. Predicted renewable generation and load.

\begin{tabular}{ccccccc}
\hline Horizon & $\mathbf{1}$ & $\mathbf{2}$ & $\mathbf{3}$ & $\mathbf{4}$ & $\mathbf{5}$ & $\mathbf{6}$ \\
\hline Renewable generation (MW) & 59.62 & 60.78 & 70.26 & 72.32 & 75.89 & 82.75 \\
Load (MW) & 370 & 330 & 290 & 260 & 280 & 350 \\
Upper limit in VSG mode (MW) & 50.68 & 51.66 & 59.72 & 61.47 & 64.51 & 70.34 \\
\hline
\end{tabular}

The standard deviation of renewable generation and load are $5 \%$ and $1 \%$ of the forecast, respectively. The lower limit of renewable generation is $40 \%$ of the forecast. The FOR of each generator is 0.01 . The cost coefficients for each unit are shown in Table 5. 
Table 5. Generation cost coefficients.

\begin{tabular}{cccccc}
\hline \multirow{2}{*}{ Generation Unit } & \multicolumn{5}{c}{ Cost Coefficients (\$/MW) } \\
& $c_{2, i}$ & $c_{1, i}$ & $c_{0, i}$ & $c_{i}^{u}$ & $c_{i}^{\boldsymbol{d}}$ \\
\hline 1 & 0.00533 & 11.699 & 231.1 & 5.835 & 5.835 \\
2 & 0.00899 & 10.333 & 200 & 5.166 & 5.166 \\
3 & 0.00741 & 10.833 & 240 & 5.417 & 5.417 \\
4 (VSG) & 0 & 0 & 0 & 4 & 4 \\
\hline
\end{tabular}

When the preset LOLP and RSP are set to be $3 \%$ and $0.1 \%$, respectively, the reserve requirements (MW) are shown in Table 6.

Table 6. Requirement for operating reserve capacity.

\begin{tabular}{ccccc}
\hline \multirow{2}{*}{ Horizon } & \multicolumn{4}{c}{ Requirements of System Overall Reserves (MW) } \\
& $\begin{array}{c}\text { RG Unit in MPPT Mode } \\
\boldsymbol{R}_{\boldsymbol{t}}^{\boldsymbol{u}}\end{array}$ & $\boldsymbol{R}_{\boldsymbol{t}}^{\boldsymbol{d}}$ & $\begin{array}{c}\text { RG Unit in VSG Mode } \\
\boldsymbol{R}_{\boldsymbol{t}}^{\boldsymbol{u}}\end{array}$ & $\boldsymbol{R}_{\boldsymbol{t}}^{\boldsymbol{d}}$ \\
\hline 1 & 12.91 & 14.254 & 11.88 & 11.1 \\
2 & 12.43 & 13.459 & 10.74 & 9.9 \\
3 & 13.48 & 13.666 & 9.31 & 8.7 \\
4 & 13.59 & 13.361 & 8.35 & 7.8 \\
5 & 14.41 & 14.147 & 8.99 & 8.4 \\
6 & 15.68 & 16.258 & 11.24 & 10.5 \\
\hline
\end{tabular}

From Table 6, in MPPT mode, RG aggravates the total reserve requirement. However, in VSG mode, the overall reserve requirement is reduced, which is equal to the original system (without the integration of RG).

The generation schemes for SGs and the IBG unit are shown in Figures 12 and 13.

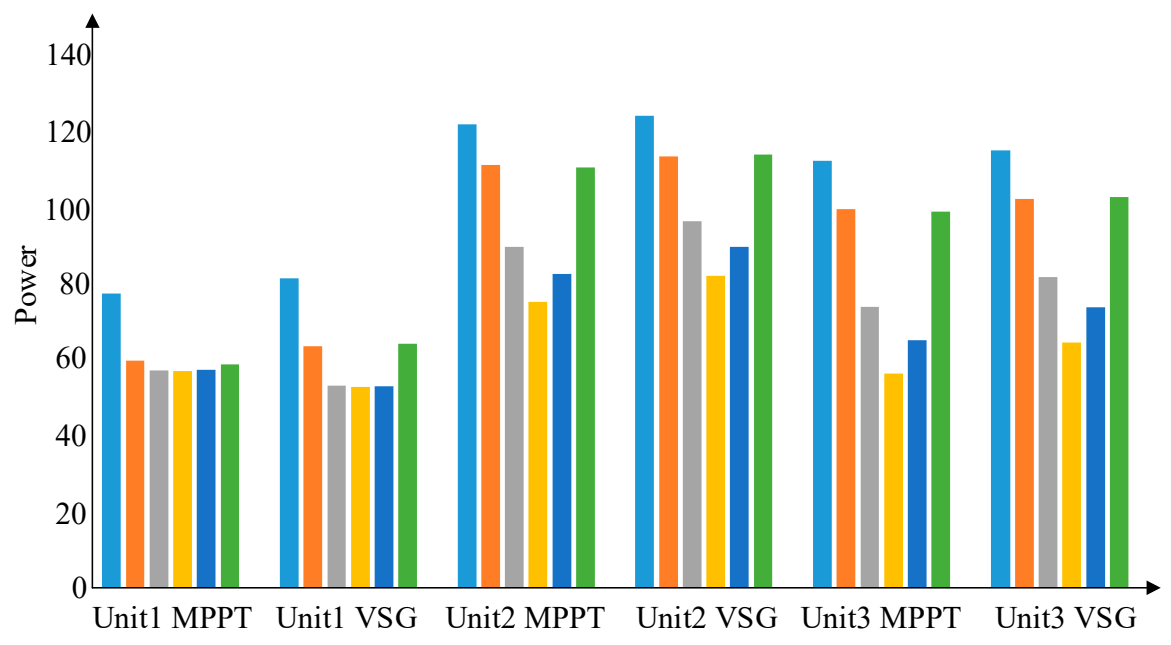

Figure 12. Generation scheme of SGs when the IBG is in VSG or MPPT mode. 


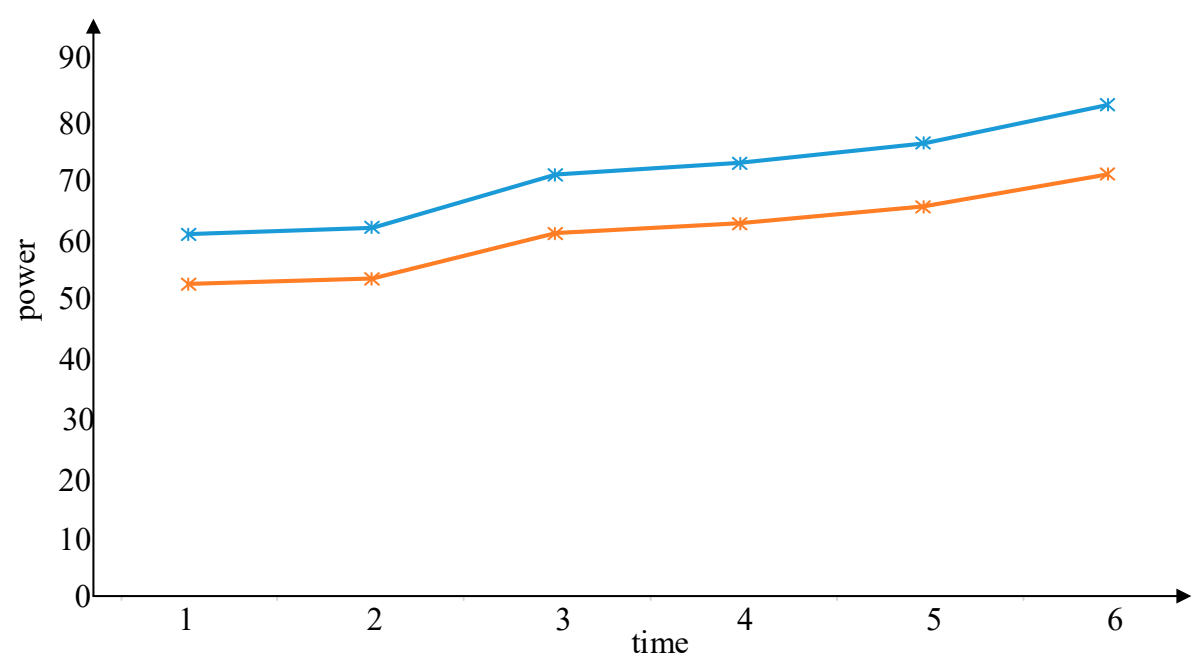

Figure 13. Generation scheme of RG.

From Figures 12 and 13, in MPPT mode, RG output equals the forecast value. In VSG mode, RG output is at its upper limit. This is because the generation cost of $R G$ is set to be zero. The discrepancy between the forecast and upper limit of RG is determined by its standard deviation. The power vacancy is provided by other SGs. The generation schemes of SGs fluctuate inconsistently with the change of load.

The reserve schemes for the IBG unit in MPPT and VSG mode are shown in Figures 14 and 15 From Figure 14, VSG-based RG units participating in system regulation would decrease the requirement of the upward reserve. The upward reserve allocated for RG is zero because the operating point for VSG-RG is set at its upper limit. From the fluctuation properties in each scenario, when the RG unit is under MPPT control, the upward reserve is determined according to the forecast uncertainties of the renewable generation and load. When the RG unit is under VSG control, the upward reserve is determined according to the uncertainty of the load forecast only. The requirement of the total upward reserve in the VSG scenario is identical to that of the original system. By considering N-1 constraints, the upward reserve is equally allocated between SGs.

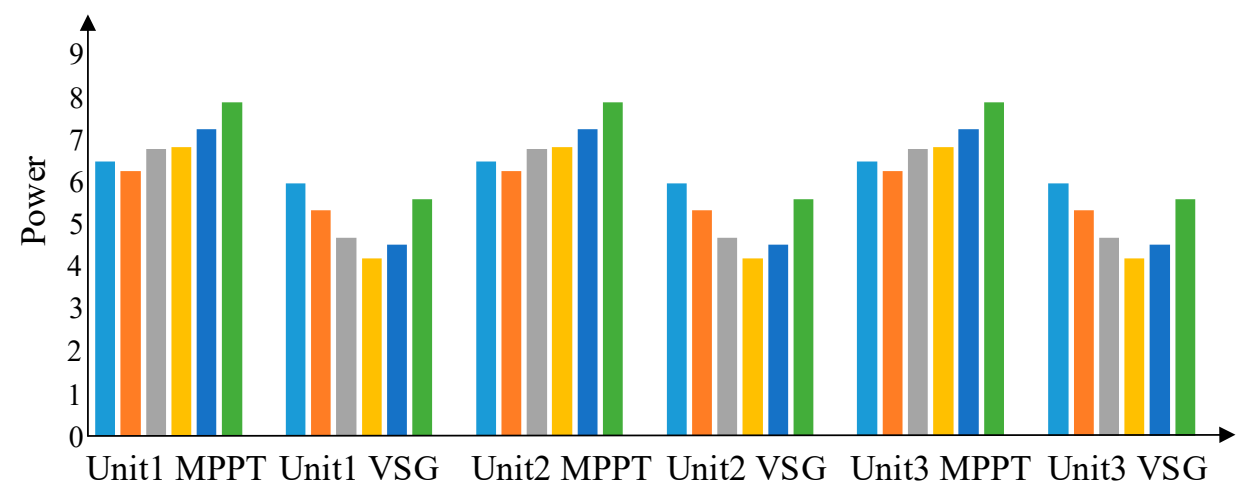

Figure 14. Upward reserve allocated for SGs with RG under MPPT or VSG mode. 


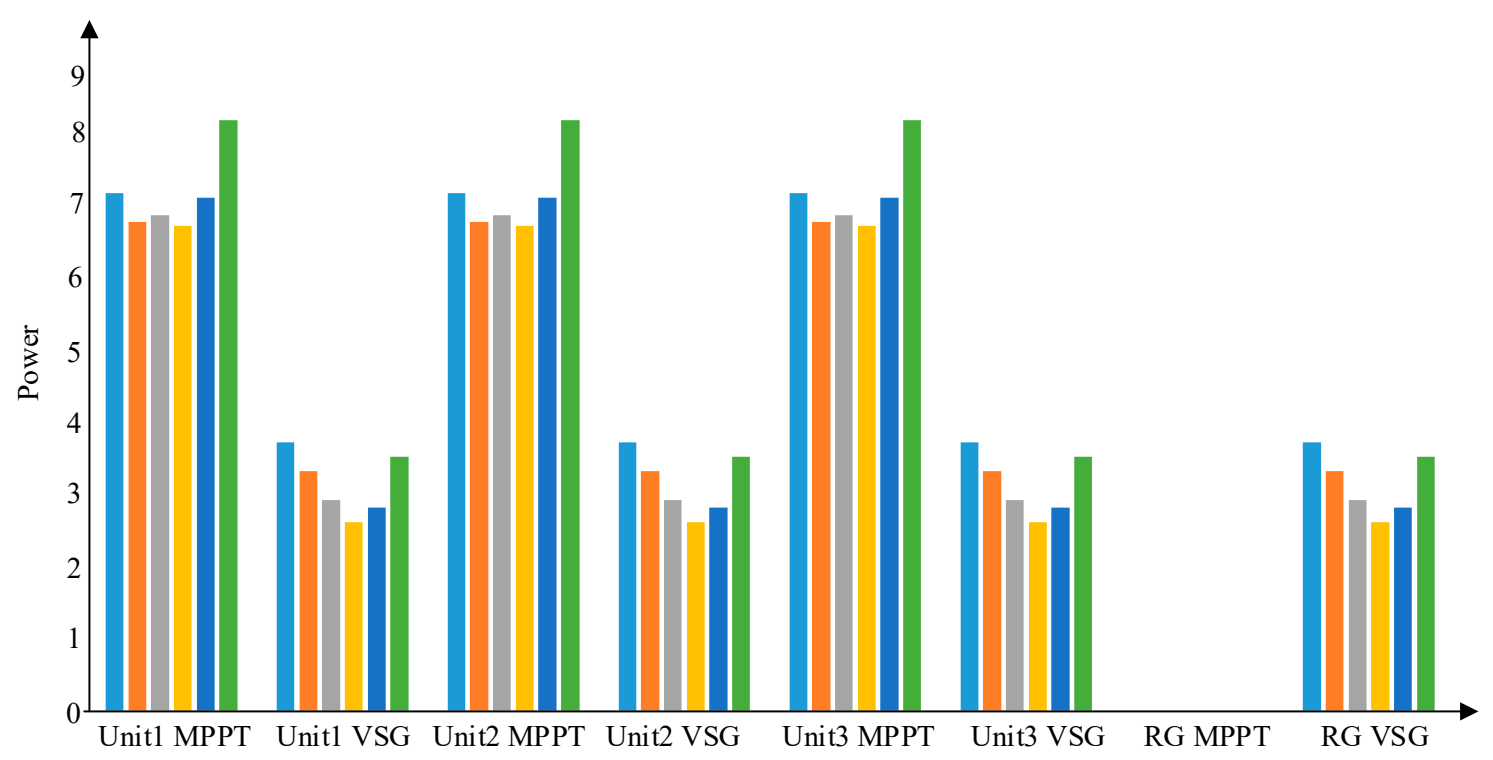

Figure 15. Downward reserve allocation for SGs and RG under MPPT or VSG mode.

When the output of IBG unit 4 is fixed at its output limits, it cannot provide supporting power counteracting frequency dips. If the overall inertia property is insufficient, extra inertial reserves should be considered. The ROCOF can be expressed as

$$
R O C O F=\frac{d \Delta f}{d t}=\frac{\Delta P}{2 H}
$$

where $\Delta P$ is the step change of load, $H$ is the inertia constant of the IBG unit. In power systems, the typical values of the system inertia constant $H_{s y s}$ and a large step increase of load $\Delta P_{\text {load }}$ are 5 and $3 \%-5 \%$, respectively $[5,13]$, then the maximum derivative of frequency $\left(R O C O F_{\max }\right)$ can be obtained.

In a synchronous area, the system inertia could be expressed as [36,39]:

$$
H_{s y s}=\sum_{i=1}^{n}\left(H_{i} \frac{S_{i}}{S_{s y s}}\right)
$$

where $i$ is the sequence number of the generation unit. By Equation (32), the required inertia constant $H_{I B G}$ for the IBG unit (if its inertia property is needed) can be obtained. Therefore, when the overall inertia property is insufficient, the inertia reserve $\Delta P_{I R}$ can be expressed as

$$
\Delta P_{I R}=2 H_{I B G} \cdot R O C O F_{\max }
$$

and the scheduled power $P_{\text {schedule }}$ for the IBG unit can be expressed as

$$
P_{4, t}^{R}{ }^{\prime}=P_{4, t}^{R}-\Delta P_{I R}
$$

From Figure 15, VSG-based RG participating in system regulation would decrease the need for a downward reserve. Furthermore, the downward reserve allocated for each generation unit is reduced. Based on the fluctuation properties in each scenario, when the RG unit is under MPPT mode, the downward reserve is determined according to the forecast uncertainties of the renewable generation and load. When the RG unit is under VSG mode, the downward reserve is determined according to the uncertainties of the load forecast only. The requirement of the total downward reserve in the VSG scenario is identical to that of the original system. By considering N-1 constraints, the downward reserve is equally allocated between traditional SGs and VSG-RG. 
The total operation cost of the two tested scenarios is shown in Table 7, which indicates that there is no significant discrepancy.

Table 7. Total operation cost.

\begin{tabular}{ccc}
\hline Operation Mode & RG Unit under MPPT & RG Unit under VSG \\
\hline Operation cost $(\$)$ & 22,651 & 22,350 \\
\hline
\end{tabular}

At every time step, under the VSG control, renewable penetration $p_{\text {ren }}$ can be calculated as [40]:

$$
p_{\text {ren }}=\frac{P_{R G}}{L_{\text {served }}}
$$

where $P_{R G}$ is total renewable generation at a certain time step, $L_{\text {served }}$ is the load served in this time step. Then, from Table 8 , the maximum renewable penetration is $23.6 \%$.

Table 8. The renewable penetration in the case study time step.

\begin{tabular}{ccccccc}
\hline & $\mathbf{1}$ & $\mathbf{2}$ & $\mathbf{3}$ & $\mathbf{4}$ & $\mathbf{5}$ & $\mathbf{6}$ \\
\hline Renewable output (MW) & 50.68 & 51.66 & 59.72 & 61.47 & 64.51 & 70.34 \\
\hline Load served (MW) & 370 & 330 & 290 & 260 & 280 & 350 \\
\hline Renewable penetration & $13.7 \%$ & $15.7 \%$ & $20.6 \%$ & $23.6 \%$ & $23.0 \%$ & $20.1 \%$ \\
\hline
\end{tabular}

Moreover, scenarios where the renewable generation forecast is halved and doubled while the load remains constant are also considered to see the impacts of different penetration levels on the economic dispatch. Under different penetration levels, a comparison of the results is shown in Table 9.

Table 9. Predicted renewable generation and load.

\begin{tabular}{cccc}
\hline Maximum Penetration Level (\%) & 13.9 & 23.6 & 55.6 \\
\hline Operation cost with MPPT-based IBG (\$) & 24,782 & 22,651 & Infeasible \\
\hline Operation cost with VSG-based IBG (\$) & 24,544 & 22,350 & 18,101 \\
\hline
\end{tabular}

From Table 9, it can be seen that the exploitation of renewable power can reduce the generation cost with growing penetration level. However, high penetration of MPPT-based renewable generation may not be feasible under certain reliability criteria. When IBG is under VSG control, it satisfies the operation constraints, and economical dispatch can be achieved.

\section{Conclusions}

This paper presents emulation strategies and economic dispatch for inverter-based RG units under VSG control participating in multiple temporal frequency control homogeneously and jointly with traditional synchronous generators. Based on the previous, the conclusions are made:

(1) Generation units can be divided into two parts: the primary energy input and the electric power generation. For PEI-based renewable generation, the external properties can be designed through the programmable supplementary controller to emulate those of traditional synchronous generators. The IBG operates mainly in two modes: the MPPT mode and the VSG mode. Based on the proposed VSG algorithm, the IBG can perform multiple temporal frequency control. Therefore, the IBG could participate in system frequency regulation.

(2) The uncertainty of renewable generation is assumed to obey Gaussian distribution. Based on the properties of Gaussian distribution, the generation uncertainty of VSG-RG is eliminated by setting 
an upper output limit at each time period. After the transformation, the generation profiles of the renewable units are homogeneous with those of SGs, and the renewable generation could be scheduled as system reserves.

(3) A generation-reserve co-optimization model was built and solved to acquire the economic dispatch schemes. Based on the results, the integration of VSG-RG will not aggravate the requirements of the system reserves. Furthermore, VSG-based IBG can be allocated part of the reserve, decreasing the burden of other SGs.

Towards power systems with high-penetration renewable generation or even $100 \%$ renewables, the proposed approach provides a preliminary solution.

Author Contributions: This work was carried out by W.Z. under the supervision of X.Y. The editing was mostly done by H.H. All authors have read and agreed to the published version of the manuscript.

Funding: This research was funded by National Natural Science Foundation of China-Hebei on the project of "Research on inertia characteristics and control strategy for primary frequency and voltage regulation of DFIG" (No. E201802134).

Conflicts of Interest: The authors declare no conflict of interest.

\section{Nomenclature}

1 Emulation control part

$H_{S G}$

$J_{S G}$

$\omega_{r}$

$V A_{\text {base }}$

$H_{\text {vir }}$

$J_{\text {vir }}$

$\omega_{m}$

$Y$

$R$

$F_{H P}$

$T_{C H}$

$T_{R H}$

$\tau$

$K_{I}$

$f_{p w m}$

2 Economic Dispatch Part

$t$

$\Delta P_{t}^{R}$

$r_{t}$

$\Delta P_{t}^{D}$

$d_{t}$

$\Delta P_{t}^{N}$

$p^{F O}$

$p_{t}^{L O L P}$

N

$i$

$R_{t}^{u}$

$P_{i}^{M A X}$

$p_{t}^{R S P}$

$R_{t}^{d}$
Inertia constant of SG

Moment of inertia of SG

Angular speed of the rotor

Rated power

Virtual inertia constant of VSG

Virtual moment of inertia of VSG

Virtual angular speed

Valve position

Speed droop

Factor of total turbine power generated by high pressure section

Time constant of main inlet volumes and steam chest

Time constant of reheater

SFR activation time

Integral coefficient of SFR

Frequency of the carrier wave

Sequence number of dispatch periods

Forecast error of renewable generation at period $t$

Standard deviation of $\Delta P_{t}^{R}$ at period $t$

Forecast error of demand at period $t$

Standard deviation of $\Delta P_{t}^{D}$ at period $t$

Forecast error of net load at period $t$

Probability of forced outage rate of SG

Loss of load probability at period $t$

Number of generation units

Serial number of the $i$-th SG

Total upward reserve at period $t$

Upper output limit of generator $i$

Renewable spillage probability at period $t$

Total downward reserve at period $t$ 


\begin{tabular}{|c|c|}
\hline$p_{\text {rated }}^{L O L P}$ & Rated probability of LOLP \\
\hline$p_{\text {rated }}^{R S P}$ & Rated probability of RSP \\
\hline$P_{t}^{R}$ & Renewable generation at period $t$ \\
\hline$P_{t}^{F R}$ & Forecast power of renewable generation at period $t$ \\
\hline$P_{t, \max }^{R}$ & Upper limit of renewable generation at period $t$ \\
\hline$P_{i, t}^{G}$ & Output power of unit $i$ at period $t$ \\
\hline$f_{C_{i}}\left(P_{i, t}^{G}\right)$ & Quadratic cost function of unit $i$ at period $t: c_{2, i}\left(P_{i, t}^{G}\right)^{2}+c_{1, i} P_{i, t}^{G}+c_{0, i}$ \\
\hline$C_{1, t}$ & Generation cost part of the total cost at period $t$ \\
\hline$r_{i, t}^{u}$ & Upward reserve of unit $i$ at period $t$ \\
\hline$r_{i, t}^{d, l}$ & Downward reserve of unit $i$ at period $t$ \\
\hline$c_{i}^{u}$ & Cost coefficient of unit $i$ for upper reserve \\
\hline$c_{i}^{d}$ & Cost coefficient of unit $i$ for downward reserve \\
\hline$C_{2, t}$ & Reserve cost part of the total cost at period $t$ \\
\hline$T$ & The number of dispatch periods \\
\hline G & The set of synchronous generator plants \\
\hline$R$ & The set of renewable generation plants \\
\hline$D$ & The set of demand \\
\hline$u$ & Upward \\
\hline$d$ & Downward \\
\hline$P_{r a m p, i}^{u}$ & Upward ramp rate \\
\hline$P_{\text {ramp }, i}^{d}$ & Downward ramp rate \\
\hline$\Delta T$ & Dispatch interval \\
\hline$T_{r}$ & Reserve dispatch interval \\
\hline$p_{\text {pen }}$ & Penetration of renewable generation \\
\hline$P_{R G}$ & Renewable output in a time step \\
\hline$L_{\text {served }}$ & Load served in a time step \\
\hline 3 Acronyms & \\
\hline DSO & Distribution system operator \\
\hline ED & Economic dispatch \\
\hline IBG & Inverter-based generation \\
\hline IIR & Instantaneous inertial response \\
\hline IR & Inertial response \\
\hline LOLP & Loss of load probability \\
\hline MPP & Maximum power point \\
\hline MPPT & Maximum power point tracking \\
\hline PEI & Power electronic interfaces \\
\hline PFR & Primary frequency response \\
\hline RES & Renewable energy sources \\
\hline RG & Renewable generation \\
\hline ROCOF & Rate of change of frequency \\
\hline RSP & Renewable spillage probability \\
\hline SFD & Second frequency droop \\
\hline SFR & Secondary frequency regulation \\
\hline SG & Synchronous generator \\
\hline $\mathrm{SO}$ & System operator \\
\hline TFR & Tertiary frequency regulation \\
\hline TSO & Transmission system operator \\
\hline VSG & Virtual synchronous generator \\
\hline VSI & Voltage-sourced inverters \\
\hline
\end{tabular}




\section{References}

1. Yan, X.; Zhang, W. Review of VSG control-enabled universal compatibility architecture for future power systems with high-penetration renewable generation. Appl. Sci. 2019, 9, 1484. [CrossRef]

2. Lopes, J.A.P.; Hatziargyriou, N.; Mutale, J.; Djapic, P.; Jenkins, N. Integrating distributed generation into electric power systems: A review of drivers, challenges and opportunities. Electr. Power Syst. Res. 2007, 77, 1189-1203. [CrossRef]

3. US Energy Information Administration. Annual Energy Outlook 2019. Available online: https://www.eia. gov/outlooks/aeo/pdf/aeo2019.pdf (accessed on 30 December 2019).

4. BP Energy Outlook 2018. Available online: https://www.bp.com/en/global/corporate/energyeconomics/ energyoutlook.html (accessed on 30 December 2019).

5. Delille, G.; Francois, B.; Malarange, G. Dynamic frequency control support by energy storage to reduce the impact of wind and solar generation on isolated power system's inertia. IEEE Trans. Sustain. Energy 2012, 3, 931-939. [CrossRef]

6. Rocabert, J.; Luna, A.; Blaabjerg, F.; Rodríguez, P. Control of Power Converters in AC Microgrids. IEEE Trans. Power Electron. 2012, 27, 4734-4749. [CrossRef]

7. Doherty, R.; O'Malley, M. A new approach to quantify reserve demand in systems with significant installed wind capacity. IEEE Trans. Power Syst. 2005, 20, 587-595. [CrossRef]

8. Ullah, N.R.; Thiringer, T.; Karlsson, D. Voltage and transient stability support by wind farms complying with the E.ON netz grid code. IEEE Trans. Power Syst. 2007, 22, 1647-1656. [CrossRef]

9. Beck, H.-P.; Hesse, R. Virtual synchronous machine. In Proceedings of the 2007 9th International Conference on Electrical Power Quality and Utilisation, Barcelona, Spain, 9-11 October 2007.

10. Driesen, J.; Visscher, K. Virtual synchronous generators. In Proceedings of the 2008 IEEE Power and Energy Society General Meeting-Conversion and Delivery of Electrical Energy in the 21st Century, Pittsburgh, PA, USA, 20-24 July 2008.

11. Zhong, Q.; Weiss, G. Synchronverters: Inverters that mimic synchronous generators. IEEE Trans. Ind. Electron. 2011, 58, 1259-1267. [CrossRef]

12. Wu, H.; Ruan, X.; Yang, D.; Chen, X.; Zhao, W.; Lv, Z.; Zhong, Q. Small-signal modeling and parameters design for virtual synchronous generators. IEEE Trans. Ind. Electron. 2016, 63, 4292-4303. [CrossRef]

13. Liu, J.; Miura, Y.; Ise, T. Comparison of dynamic characteristics between virtual synchronous generator and droop control in inverter-based distributed generators. IEEE Trans. Power Electron. 2016, 31, 3600-3611. [CrossRef]

14. Zhong, Q.C. Virtual synchronous machines and autonomous power systems. Proc. CSEE 2017, 37, 336-349.

15. Liu, H.; Chen, Z. Contribution of VSC-HVDC to frequency regulation of power systems with offshore wind generation. IEEE Trans. Energy Convers. 2015, 30, 918-926. [CrossRef]

16. Díaz-González, F.; Hau, M.; Sumper, A.; Gomis-Bellmunt, O. Participation of wind power plants in system frequency control: Review of grid code requirements and control methods. Renew. Sustain. Energy Rev. 2014, 34, 551-564. [CrossRef]

17. Liu, D.; Zhong, Q.; Wang, Y.; Liu, G. Modeling and control of a V2G charging station based on synchronverter technology. CSEE J. Power Energy Syst. 2018, 4, 326-338. [CrossRef]

18. Ye, Y.; Qiao, Y.; Lu, Z. Revolution of frequency regulation in the converter-dominated power system. Renew. Sustain. Energy Rev. 2019, 111, 145-156. [CrossRef]

19. NREL. Flexibility in 21st Century Power Systems. Available online: https://www.nrel.gov/docs/fy14osti/ 61721.pdf (accessed on 30 December 2019).

20. National Grid ESO. Interim Report into the Low Frequency Demand Disconnection (LFDD) Following Generator Trips and Frequency Excursion on 9 Aug 2019. Ofgem., UK. Available online: https: //www.ofgem.gov.uk/system/files/docs/2019/08/incident_report_lfdd_-_summary_-_final.pdf (accessed on 30 December 2019).

21. Dany, G. Power reserve in interconnected systems with high wind power production. In Proceedings of the 2001 IEEE Porto Power Tech Proceedings (Cat. No.01EX502), Porto, Portugal, 10-13 September 2001.

22. Bouffard, F.; Galiana, F.D. An electricity market with a probabilistic spinning reserve criterion. IEEE Trans. Power Syst. 2004, 19, 300-307. [CrossRef] 
23. Pozo, D.; Contreras, J. A chance-constrained unit commitment with an n-k security criterion and significant wind generation. IEEE Trans. Power Syst. 2013, 28, 2842-2851. [CrossRef]

24. Liu, K.; Qu, Y.; Kim, H.-M.; Song, H. Avoiding Frequency Second Dip in Power Unreserved Control During Wind Power Rotational Speed Recovery. IEEE Trans. Power Syst. 2018, 33, 3097-3106. [CrossRef]

25. Wu, Z.; Gao, D.W.; Zhang, H.; Yan, S.; Wang, X. Coordinated Control Strategy of Battery Energy Storage System and PMSG-WTG to Enhance System Frequency Regulation Capability. IEEE Trans. Sustain. Energy 2017, 8, 1330-1343. [CrossRef]

26. Kang, M.; Kim, K.; Muljadi, E.; Park, J.-W.; Kang, Y.C. Frequency control support of a doubly-fed induction generator based on the torque limit. IEEE Trans. Power Syst. 2016, 31, 4575-4583. [CrossRef]

27. Ullah, N.R.; Thiringer, T.; Karlsson, D. Temporary primary frequency control support by variable speed wind turbines-Potential and applications. IEEE Trans. Power Syst. 2008, 3, 601-612. [CrossRef]

28. Ochoa, D.; Martinez, S. Fast-Frequency response provided by dfig-wind turbines and its impact on the grid. IEEE Trans. Power Syst. 2017, 32, 4002-4011. [CrossRef]

29. Ye, Y.; Lu, Z.; Xie, L.; Qiao, Y. A coordinated frequency regulation strategy for VSC-HVDC integrated offshore wind farms. In Proceedings of the 2018 IEEE Power \& Energy Society General Meeting (PESGM), Portland, OR, USA, 5-10 August 2018.

30. Zertek, A.; Verbic, G.; Pantos, M. A novel strategy for variable-speed wind turbines' participation in primary frequency control. IEEE Trans. Sustain. Energy 2012, 3, 791-799. [CrossRef]

31. Vidyanandan, K.V.; Senroy, N. Primary frequency regulation by deloaded wind turbines using variable droop. IEEE Trans. Power Syst. 2013, 28, 837-846. [CrossRef]

32. Kundur, P. Power System Stability and Control; McGrawHill: NewYork, NY, USA, 1993.

33. Alsiraji, H.A.; El-Shatshat, R. Comprehensive assessment of virtual synchronous machine based voltage source converter controllers. IET Gener. Transm. Distrib. 2017, 11, 1762-1769. [CrossRef]

34. D'Arco, S.; Suul, J.A. Virtual Synchronous Machines-Classification of Implementations and Analysis of Equivalence to Droop Controllers for Microgrid. In Proceedings of the IEEE Powertech Grenoble Conference, Grenoble, France, 16-20 June 2013.

35. Zhou, M.; Wang, M.; Li, J.; Li, G. Multi-area generation-reserve joint dispatch approach considering wind power cross-regional accommodation. CSEE J. Power Energy Syst. 2017, 3, 74-83. [CrossRef]

36. Tan, Y.; Meegahapola, L.; Muttaqi, K.M. A Suboptimal Power-Point-Tracking-Based Primary Frequency Response Strategy for DFIGs in Hybrid Remote Area Power Supply Systems. IEEE Trans. Energy Convers. 2016, 31, 93-105. [CrossRef]

37. Margaris, I.D.; Papathanassiou, S.A.; Hatziargyriou, N.D.; Hansen, A.D.; Sorensen, P. Frequency control in autonomous power systems with high wind power penetration. IEEE Trans. Sustain. Energy 2012, 3, 189-199. [CrossRef]

38. Wood, J.; Wollenberg, B.F.; Sheblé, G.B. Power Generation, Operation and ControlI, 3rd ed.; Wiley: New Jersey, NJ, USA, 2013.

39. Ekanayake, J.B.; Jenkins, N.; Strbac, G. Frequency response from wind turbines. Wind Eng. 2008, 32, 573-586. [CrossRef]

40. Homer. Available online: https://www.homerenergy.com/products/pro/docs/latest/renewable_penetration. html (accessed on 2 February 2020).

(C) 2020 by the authors. Licensee MDPI, Basel, Switzerland. This article is an open access article distributed under the terms and conditions of the Creative Commons Attribution (CC BY) license (http://creativecommons.org/licenses/by/4.0/). 